\title{
Fabrication of multi-well chips for spheroid cultures and implantable constructs through rapid prototyping techniques
}

Citation for published version (APA):

Lopa, S., Piraino, F., Kemp, R. J., Di Caro, C., Lovati, A. B., Di Giancamillo, A., Moroni, L., Peretti, G. M., Rasponi, M., \& Moretti, M. (2015). Fabrication of multi-well chips for spheroid cultures and implantable constructs through rapid prototyping techniques. Biotechnology and Bioengineering, 112(7), $1457-1471$. https://doi.org/10.1002/bit.25557

Document status and date:

Published: 01/07/2015

DOI:

10.1002/bit.25557

Document Version:

Publisher's PDF, also known as Version of record

\section{Document license:}

Taverne

Please check the document version of this publication:

- A submitted manuscript is the version of the article upon submission and before peer-review. There can be important differences between the submitted version and the official published version of record.

People interested in the research are advised to contact the author for the final version of the publication, or visit the DOI to the publisher's website.

- The final author version and the galley proof are versions of the publication after peer review.

- The final published version features the final layout of the paper including the volume, issue and page numbers.

Link to publication

\footnotetext{
General rights rights.

- You may freely distribute the URL identifying the publication in the public portal. please follow below link for the End User Agreement:

www.umlib.nl/taverne-license

Take down policy

If you believe that this document breaches copyright please contact us at:

repository@maastrichtuniversity.nl

providing details and we will investigate your claim.
}

Copyright and moral rights for the publications made accessible in the public portal are retained by the authors and/or other copyright owners and it is a condition of accessing publications that users recognise and abide by the legal requirements associated with these

- Users may download and print one copy of any publication from the public portal for the purpose of private study or research.

- You may not further distribute the material or use it for any profit-making activity or commercial gain

If the publication is distributed under the terms of Article $25 \mathrm{fa}$ of the Dutch Copyright Act, indicated by the "Taverne" license above, 


\title{
Fabrication of Multi-Well Chips for Spheroid Cultures and Implantable Constructs Through Rapid Prototyping Techniques
}

\author{
Silvia Lopa, ${ }^{1}$ Francesco Piraino, ${ }^{2}$ Raymond J. Kemp, ${ }^{3}$ Clelia Di Caro, ${ }^{2}$ \\ Arianna B. Lovati, ${ }^{1}$ Alessia Di Giancamillo, ${ }_{4}^{4}$ Lorenzo Moroni, ${ }^{3,5}$ Giuseppe M. Peretti, ${ }^{4,6}$ \\ Marco Rasponi, ${ }^{2}$ Matteo Moretti ${ }^{1}$ \\ ${ }^{1}$ Cell and Tissue Engineering Laboratory, IRCCS Galeazzi Orthopaedic Institute, Via R. \\ Galeazzi 4 20161, Milan, Italy; telephone: +39-026-621-4049; fax: +39-026-621-4060; \\ e-mail: matteo.moretti@grupposandonato.it \\ ${ }^{2}$ Department of Electronics, Information, and Bioengineering, Politecnico di Milano, \\ Milan 20133, Italy \\ ${ }^{3}$ Tissue Regeneration Department, University of Twente, 7522 NB, Enschede, \\ The Netherlands \\ ${ }^{4}$ IRCCS Galeazzi Orthopaedic Institute, Milan 20161, Italy \\ ${ }^{5}$ Department of Complex Tissue Regeneration, Maastricht University, 6200 MD, \\ Maastricht, The Netherlands \\ ${ }^{6}$ Department of Biomedical Sciences for Health, Università degli Studi di Milano, \\ Milan 20161, Italy
}

\begin{abstract}
Three-dimensional (3D) culture models are widely used in basic and translational research. In this study, to generate and culture multiple 3D cell spheroids, we exploited laser ablation and replica molding for the fabrication of polydimethylsiloxane (PDMS) multi-well chips, which were validated using articular chondrocytes (ACs). Multi-well ACs spheroids were comparable or superior to standard spheroids, as revealed by glycosaminoglycan and type-II collagen deposition. Moreover, the use of our multi-well chips significantly reduced the operation time for cell seeding and medium refresh. Exploiting a similar approach, we used clinicalgrade fibrin to generate implantable multi-well constructs allowing for the precise distribution of multiple cell types. Multi-well fibrin constructs were seeded with ACs generating high cell density regions, as shown by histology and cell fluorescent staining. Multiwell constructs were compared to standard constructs with homogeneously distributed ACs. After 7 days in vitro, expression of SOX9, ACAN, COL2A1, and COMP was increased in both constructs, with multi-well constructs expressing significantly higher levels of chondrogenic genes than standard constructs. After 5 weeks in vivo, we found that despite a dramatic size reduction, the
\end{abstract}

Disclosure statement: The authors have no competing interests to declare. Silvia Lopa and Francesco Piraino contributed equally to this paper.

F. Piraino's present address is Institute of Bioengineering, School of Engineering, École Polytechnique Fédérale de Lausanne, Lausanne, Switzerland Correspondence to: M. Moretti

Received 3 October 2014; Revision received 23 January 2015; Accepted 26 January 2015

Accepted manuscript online 10 February 2015;

Article first published online 10 March 2015 in Wiley Online Library

(http://onlinelibrary.wiley.com/doi/10.1002/bit.25557/abstract).

DOI 10.1002/bit.25557 cell distribution pattern was maintained and glycosaminoglycan content per wet weight was significantly increased respect to preimplantation samples. In conclusion, multi-well chips for the generation and culture of multiple cell spheroids can be fabricated by low-cost rapid prototyping techniques. Furthermore, these techniques can be used to generate implantable constructs with defined architecture and controlled cell distribution, allowing for in vitro and in vivo investigation of cell interactions in a 3D environment.

Biotechnol. Bioeng. 2015;112: 1457-1471.

(C) 2015 Wiley Periodicals, Inc.

KEYWORDS: rapid prototyping; 3D model; cell spheroid; implantable scaffold; tissue engineering

\section{Introduction}

Three-dimensional (3D) cultures are widely used as in vitro models for cell culture. Compared with monolayer cultures, 3D models better mimic the in vivo tissue features, thus providing a physiologically relevant environment [Abbott, 2003]. Among different types of 3D models developed in the past years, multiple cell aggregates or spheroids have been widely used in tumor [Burdett et al., 2010] and tissue engineering [Fennema et al., 2013] research areas. The screening of multiple drugs or culture conditions through 3D cell spheroids requires a relevant number of experimental replicates with cells from different donors, thus 
making the use of this 3D model more complex and time consuming compared to conventional monolayer cultures. 3D spheroids, whereby specific extracellular matrix is produced by aggregated cells, also represent the living "building blocks" in organ printing, which aims at the layer-by-layer biofabrication of $3 \mathrm{D}$ functional tissues and organs [Boland et al., 2003; Jakab et al., 2004; Mironov et al., 2009].

The need to generate cell spheroids in a high-throughput fashion for cancer research and for basic and translational tissue engineering studies has encouraged the development of multiwell devices as an alternative to standard methods for the formation and culture of multiple 3D cell spheroids [Babur et al., 2013; de Ridder et al., 2000; Moreira Teixeira et al., 2012; Ratnayaka et al., 2013]. Indeed, these devices provide a relevant tool to implement 3D spheroid models, reducing the time required for routine operations and minimizing differences between experimental replicates.

Rapid prototyping techniques represent an exceptional tool to generate easy-handling platforms for 3D cell culture. However, existing lithography-based approaches are often expensive and time consuming [Whitesides et al., 2001]. Indeed, current approaches based on lithographic fabrication require cleanroom facilities where any minor change in the design involves increasing costs related to the fabrication process. Laser fabrication techniques offer an alternative to lithography-based approaches for rapid prototyping [Becker and Gartner, 2008] and have been recently exploited for the fabrication of micro-wells in order to minimize fabrication complexity [Napolitano et al., 2007; Piraino et al., 2012b; Selimovic et al., 2011].

Another key element for developing innovative 3D models is the possibility of generating scaffolds with a controlled micro- and/or macro-scale architecture, directing cell distribution and/or cell orientation by topographical cues [Bae et al., 2014; Gerberich and Bhatia, 2013]. Implantable multi-well scaffolds have recently been proposed for the in vivo evaluation of the influence of different extracellular matrix components on the differentiation of cells seeded within the wells [Higuera et al., 2013], demonstrating the great potentiality of this approach.

In this study we exploited laser ablation and replica molding to fabricate multi-well polydimethylsiloxane (PDMS) chips for the culture of multiple cell spheroids, using human articular chondrocytes (ACs) for their validation. ACs are widely investigated in the field of cartilage tissue engineering. Their redifferentiation, necessary to reacquire their original phenotype after in vitro expansion [Giannoni and Cancedda, 2006; Giannoni et al., 2005; Schulze-Tanzil 2009], is traditionally performed in 3D conditions [Bernstein et al., 2009; Dehne et al., 2010; Jakob et al., 2001; Zhang et al., 2004], indicating that this cell population is a suitable cell source for the validation of platforms for 3D spheroid formation and culture.

The same rapid prototyping techniques were used to biofabricate implantable multi-well fibrin constructs, allowing differential cell seeding into the construct structure and into the wells. We used a clinical-grade fibrin glue [Ahmed et al., 2008; Ahmed and Hincke, 2010; Colombini et al., 2014a; Scotti et al., 2010] to validate our biofabrication process and through differential cell staining, we verified the feasibility of precise cell seeding in different regions of the multi-well construct. As a proof of concept, we biofabricated fibrin constructs where human ACs were homogeneously dispersed or where different cell density regions were generated. Then, we evaluated cell behavior in standard and multi-well fibrin constructs after 1 and 7 days of in vitro culture and after 5 weeks of subcutaneous implantation in nude mice.

\section{Materials and Methods}

\section{Cell Isolation and Expansion}

Samples of articular cartilage were harvested from patients affected by osteoarthritis undergoing total hip replacement (five males and five females, mean age $64 \pm 8$ years), with patients' informed written consent and with the approval of the Institutional Review Board. ACs were isolated from cartilage by enzymatic digestion using $0.15 \%$ type II collagenase (Worthington Biochemical Corp., Lakewood, NJ) for $22 \mathrm{~h}$ at $37^{\circ} \mathrm{C}$, according to a previously established protocol [Lagana et al., 2014; Lopa et al., 2013]. The cells were plated at a density of $10^{4}$ cells $/ \mathrm{cm}^{2}$ and cultured in expansion medium. Expansion medium was composed as follows: high glucose Dulbecco's modified Eagle's medium (HG-DMEM, Gibco, Paisley, United Kingdom) supplemented with $10 \%$ fetal bovine serum (FBS, Lonza, Basel, Switzerland), $0.029 \mathrm{mg} / \mathrm{mL}$ L-glutamine, $100 \mathrm{U} / \mathrm{mL}$ penicillin, $100 \mathrm{mg} / \mathrm{mL}$ streptomycin, $10 \mathrm{mM}$ Hepes, $1 \mathrm{mM}$ sodium pyruvate (all from Gibco), $1 \mathrm{ng} / \mathrm{mL}$ transforming growth factor $\beta 1$ (TGF- $\beta 1$, Peprotech, Rocky Hill, NJ), and $5 \mathrm{ng} / \mathrm{mL}$ fibroblast growth factor 2 (FGF-2, Peprotech). At subconfluence, cells were detached by $0.05 \%$ trypsin $/ 0.53 \mathrm{mM}$ EDTA (Gibco) and plated at $5 \times 10^{3}$ cells $/ \mathrm{cm}^{2}$ for further expansion. At passage 2, cells were frozen and stored in liquid nitrogen. When needed, cells were thawed and expanded for one additional passage. To limit the expansion phase required to obtain a suitable number of cells, cells from different donors were pooled together to perform the experiments.

\section{Multi-Well PDMS Chips}

\section{Fabrication of PMMA Templates and Multi-Well PDMS Chips}

Drawings of PMMA master templates were made by AutoCAD ${ }^{\mathbb{R}}$ software (Autodesk, Inc., San Rafael, CA) and processed by Corel ${ }^{\circledR}$ DRAW $^{\mathrm{TM}}$ software (Corel Corporation, 2002, Ottawa, Canada). Master templates were obtained by carbon dioxide $\left(\mathrm{CO}_{2}\right)$ laser ablation of a polymethylmethacrylate (PMMA) substrate (Fig. 1a, step I) in single hole drilling mode, as previously described [Piraino et al., 2012b; Selimovic et al., 2011]. The laser power was set at $22.5 \mathrm{~W}$, the write speed at $0.08 \mathrm{~mm} / \mathrm{s}$, and $z=17.2 \mathrm{~mm}$ (VLS2.30, VersaLASER, Universal Laser Systems Inc., Scottsdale, AZ). Substrate removal through ablation produced features with a Gaussian-profile. A PDMS mixture (Sylgard ${ }^{\circledR}$ 184, Dow Corning, Midland, MI) was prepared at a 10:1 ratio (prepolymer/curing agent), degassed, poured on the PMMA master template, and baked at $70^{\circ} \mathrm{C}$ for $2 \mathrm{~h}$ (Fig. 1a, step II). Once polymerized, the PDMS was carefully peeled off the PMMA master template and cleaned with $70 \%$ EtOH. After rinsing with $\mathrm{ddH}_{2} \mathrm{O}$, PDMS multi-well chips were sterilized by autoclave. 
a

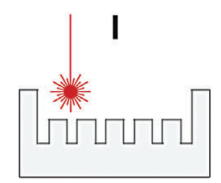

PMMA template
II

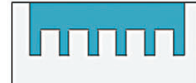

PDMS casting
III

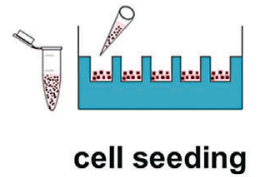

IV

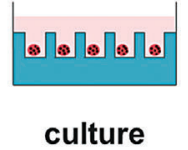

b

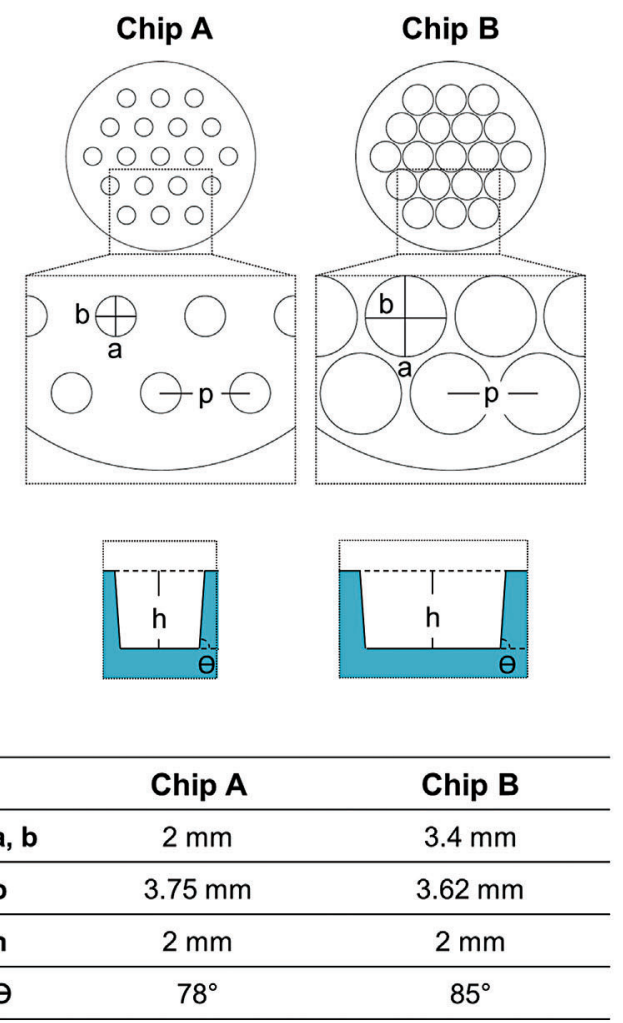

C Chip A

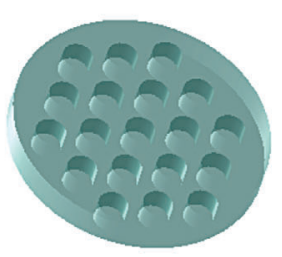

Chip B

d

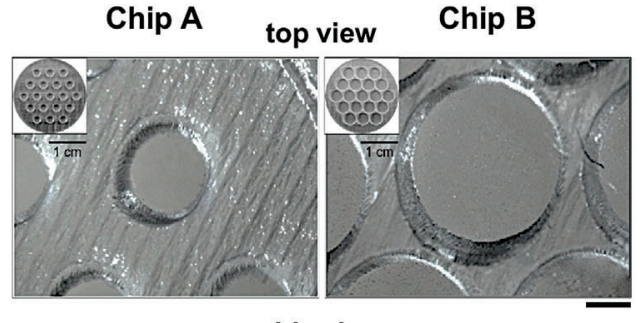

side view

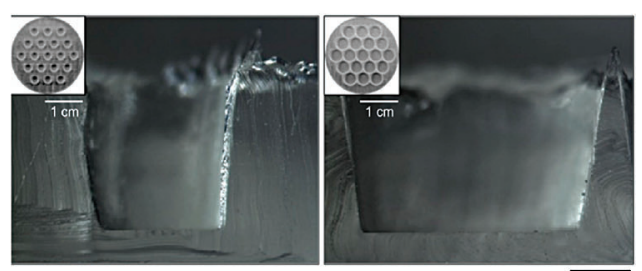

Figure 1. Fabrication of multi-well PDMS chips for cell spheroid generation and culture. (a) Laser-ablated PMMA master templates (I) were used to generate the multi-well PDMS chips (II). PDMS chips were placed in a 12-well multiwell plate, cells were seeded in the wells, and the multiwell plate was centrifuged to promote spheroid formation (III). Then, medium was added and PDMS chips were maintained in culture for 21 days (IV). (b) CAD drawing including top view with insets showing diameter, pitch, height of the wells and taper angle. Corresponding values for the two configurations (Chip A, Chip B) are indicated in table. (c) 3D rendering of Chip A and Chip B. (d) Optical images of Chip A ( $\left.\oslash_{\text {well }} 2 \mathrm{~mm}\right)$ and Chip B $\left(\oslash_{\text {well }} 3.4 \mathrm{~mm}\right)$ fabricated by PDMS replica molding (scale bars $1 \mathrm{~mm}$, except where noted).

Two different configurations of PDMS multi-well chips were designed to host 19 wells in a single chip. Features of the two multiwell chip configurations, named Chip A and Chip B, and their 3D renderings are reported respectively in Figure $1 \mathrm{~b}$ and $\mathrm{c}$.

\section{Cell Spheroid Formation}

Sterile PDMS chips were placed in a 12-well multiwell plate and each PDMS chip was seeded with a total number of $2.85 \times 10^{6}$ cells by pipetting $1.5 \times 10^{5}$ cells in each single well (Fig. 1a, step III). The 12 -well multiwell plate was then centrifuged for $5 \mathrm{~min}$ at $230 \mathrm{~g}$ to favor spheroid formation. After $2 \mathrm{~h}, 2.85 \mathrm{~mL}$ of chondrogenic medium was gently added to each well (Fig. 1a, step IV). Control (Ctrl) spheroids were prepared in $1.5 \mathrm{~mL}$ screw-cap conical tubes. Briefly, $1.5 \times 10^{5}$ cells were suspended in $150 \mu \mathrm{L}$ of chondrogenic medium, transferred to a tube, and centrifuged for $5 \mathrm{~min}$ at $230 \mathrm{~g}$.
Chondrogenic medium was composed as follows: HG-DMEM supplemented with $0.029 \mathrm{mg} / \mathrm{mL}$ L-glutamine, $100 \mathrm{U} / \mathrm{mL}$ penicillin, $100 \mu \mathrm{g} / \mathrm{mL}$ streptomycin, $10 \mathrm{mM}$ Hepes, $1 \mathrm{mM}$ sodium pyruvate, $1.25 \mathrm{mg} / \mathrm{mL}$ human serum albumin (HSA, Sigma-Aldrich, St. Louis, MO), $1 \%$ ITS +1 (containing $1.0 \mathrm{mg} / \mathrm{mL}$ insulin from bovine pancreas, $0.55 \mathrm{mg} / \mathrm{mL}$ human transferrin, $0.5 \mu \mathrm{g} / \mathrm{mL}$ sodium selenite, $50 \mathrm{mg} / \mathrm{mL}$ bovine serum albumin, and $470 \mu \mathrm{g} / \mathrm{mL}$ linoleic acid, Sigma-Aldrich), $0.1 \mu \mathrm{M}$ dexamethasone, $0.1 \mathrm{mM}$ L-ascorbic acid-2-phosphate, and $10 \mathrm{ng} / \mathrm{mL}$ TGF- $\beta 1$. Samples were cultured for 21 days $\left(37^{\circ} \mathrm{C}, 5 \% \mathrm{CO}_{2}\right)$. Medium was replaced twice per week.

\section{Measurement of Operation Time for Cell Seeding and Medium Refresh}

For spheroid culture in standard tubes and in multi-well PDMS chips, we measured the operation time required to perform cell 
seeding and medium refresh. Independent measures were obtained testing three operators with different skill levels in cell culture techniques.

\section{Spheroid Analysis}

Evaluation of spheroid area. After 7, 14, and 21 days of culture in chondrogenic medium, spheroids in the multi-well chips were photographed to monitor the size variation. Spheroid area was determined by image analysis using ImageJ software.

Quantification of Metabolic Activity and DNA Content. After 21 days of culture in chondrogenic medium, cell metabolic activity was evaluated by Alamar Blue assay. Briefly, spheroids were randomly harvested from different PDMS chips and from the tubes (control group), transferred to a 96-well multi-well plate, and incubated with $100 \mu \mathrm{L}$ HG-DMEM supplemented with 10\% Alamar Blue for $4 \mathrm{~h}$ at $37^{\circ} \mathrm{C}$. After incubation, the supernatant was harvested and fluorescence was measured (540-580 nm) using a Victor X3 Plate Reader (Perkin Elmer, Waltham, MA). The same spheroids were lysed for DNA quantification. After washing with phosphate buffered saline, spheroids were digested $\left(16 \mathrm{~h}, 60^{\circ} \mathrm{C}\right)$ in $500 \mu \mathrm{L}$ of PBE buffer ( $100 \mathrm{mM} \mathrm{Na}_{2} \mathrm{HPO}_{4}, 10 \mathrm{mM} \mathrm{NaEDTA}, \mathrm{pH}$ 6.8) containing $1.75 \mathrm{mg} / \mathrm{mL}$ L-cystein (Sigma-Aldrich) and $14.2 \mathrm{U} / \mathrm{mL}$ papain (Worthington Biochemical Corp.). DNA quantification was performed by CyQUANT Kit (Invitrogen, Carlsbad, CA), according to the manufacturer's instructions.

Histological and Immunohistochemical Analysis. For histological analysis, chondrocyte spheroids cultured for 21 days were fixed for $24 \mathrm{~h}$ in $10 \%$ neutral buffered formalin, embedded in paraffin and sectioned at $3 \mu \mathrm{m}$. Sections were stained with alcian blue ( $\mathrm{pH} 2.5$, SigmaAldrich) to detect glycosaminoglycans (GAGs). For immunohistochemistry, sections were deparaffinized, rehydrated, and treated with $3 \%$ hydrogen peroxide in distilled water for $15 \mathrm{~min}$. Mouse monoclonal anti-Collagen II antibody (SPM239, ab54236, Abcam, Cambridge, UK) was applied at room temperature for $1 \mathrm{~h}$. The sections were labeled by the avidin-biotin-peroxidase (ABC) procedure [Hsu et al., 1981] with a commercial immunoperoxidase kit (Vectastain Standard Elite; Vector Laboratories, Burlingame, CA). The immunohistochemical reaction was developed with 3.3' diaminobenzidine for $5 \mathrm{~min}$ and sections were counterstained for 2 min with Mayer's hematoxylin.

\section{Implantable Multi-Well Fibrin Constructs}

\section{Fabrication of PMMA Master Templates and PDMS Counter-Molds}

PMMA master templates and the corresponding PDMS countermolds were fabricated by $\mathrm{CO}_{2}$ laser ablation (Fig. 2a, step I) and replica molding (Fig. 2a, step II), as previously described for the fabrication of multi-well PDMS chips.

Three different configurations of PDMS molds were designed to biofabricate fibrin constructs with multi-well bottom layers containing 19, 10, or 7 wells (Fig. 2b). Features of the three different PDMS mold configurations, named Mold X, Mold Y, and
Mold Z, and their 3D renderings are reported, respectively, in Figure $2 \mathrm{~b}$ and $\mathrm{c}$. Immediately prior to use, PDMS molds were plasma treated (Harrick Plasma, Inc., Ithaca, NY) for $8 \mathrm{~min}$ to reduce surface hydrophobicity.

\section{Biofabrication of Multi-Well Fibrin Constructs}

The two-component fibrin sealant Tisseel ${ }^{\circledR}$ (Baxter Biosurgery, Vienna, Austria) was used to generate the fibrin constructs. The fibrinogen component contained $91 \mathrm{mg} / \mathrm{mL}$ human fibrinogen and $3000 \mathrm{KIU} / \mathrm{mL}$ aprotinin solution. The thrombin component was diluted to $5 \mathrm{U} / \mathrm{mL}$ in $40 \mathrm{mM}$ of $\mathrm{CaCl}_{2}$ at $\mathrm{pH} 7.0$. Initially, fibrin constructs with three different configurations of the multi-well bottom layer were prepared according to the protocol depicted in Figure 2a: (X) 19 wells, $\oslash_{\text {well }} 1 \mathrm{~mm}, \mathrm{~h}_{\text {well }} 1.5 \mathrm{~mm}$; (Y) 10 wells, $\oslash_{\text {well }} 1.5 \mathrm{~mm}$, $\mathrm{h}_{\text {well }} 1.5 \mathrm{~mm}$; (Z) 7 wells, $\oslash_{\text {well }} 2 \mathrm{~mm}, \mathrm{~h}_{\text {well }} 1.5 \mathrm{~mm}$. For each construct, $1.15 \times 10^{6}$ cells were suspended in fibrinogen and thrombin mixed at a 1:1 ratio (cell density $15.4 \times 10^{6}$ cells $/ \mathrm{mL}$ ) and poured into the PDMS molds until polymerization $\left(1 \mathrm{~h}, 37^{\circ} \mathrm{C}\right.$, Fig. 2a, step III). The bottom layer was then gently removed from the PDMS mold and transferred into a 12-well multiwell plate. Custom-made PDMS rings ( $\oslash_{\text {out }} 10 \mathrm{~mm}, \oslash_{\text {in }} 8 \mathrm{~mm}$, h $3 \mathrm{~mm}$ ) were placed around the bottom layers. Then, different cell numbers were seeded in each well, depending on the construct configuration (Fig. 2a, step IV): (X) $1 \times 10^{5}$ cells in $\oslash_{\text {well }} 1 \mathrm{~mm}$; (Y) $2 \times 10^{5}$ cells in $\oslash_{\text {well }} 1.5 \mathrm{~mm}$; (Z) $4 \times 10^{5}$ cells in $\oslash_{\text {well }} 2 \mathrm{~mm}$. After $15 \mathrm{~min}$, a fibrin top layer ( $\oslash 8 \mathrm{~mm}, \mathrm{~h} 1 \mathrm{~mm}$ ) was generated by suspending $8.5 \times 10^{5}$ cells with fibrinogen and thrombin mixed at a 1:1 ratio (cell density $15.4 \times 10^{6}$ cells $/ \mathrm{mL}$ ) and pouring the mixture over the multi-well bottom layer (Fig. 2a, step V). In this phase, the PDMS ring was used to match the bottom layer shape and to avoid fibrin leaking. After polymerization, the PDMS ring was removed and constructs were cultured in $3 \mathrm{~mL}$ chondrogenic medium (Fig. 2a, step VI). After selecting the best bottom layer configuration based on the reproducibility of construct fabrication and cell seeding into the wells, we compared the multi-well fibrin constructs (10 wells, $\oslash_{\text {well }} 1.5 \mathrm{~mm}, \mathrm{~h}_{\text {well }} 1.5 \mathrm{~mm}, 2 \times 10^{5}$ cells/well) with a similar construct without wells. Both types of fibrin constructs $(\oslash 8 \mathrm{~mm}, \mathrm{~h}$ $3 \mathrm{~mm}$ ) were seeded with a total number of $4 \times 10^{6}$ cells. Bottom and top layer of the multi-well fibrin constructs were prepared as aforementioned. To seed the wells of the constructs, a cell suspension with a density of $10^{8}$ cells $/ \mathrm{mL}$ was prepared. In each well, we added $2 \mu \mathrm{L}$ of cell suspension corresponding to $2 \times 10^{5}$ cells. To prepare standard fibrin constructs without wells, $4 \times 10^{6}$ cells were suspended in fibrinogen and thrombin mixed at a 1:1 ratio (cell density $26.7 \times 10^{6}$ cells $/ \mathrm{mL}$ ). The mixture was poured into the custom-made PDMS rings and let polymerize for $1 \mathrm{~h}$ at $37^{\circ} \mathrm{C}$. After polymerization, all constructs were cultured in $3 \mathrm{~mL}$ chondrogenic medium.

\section{Fibrin Construct Analysis}

Evaluation of Multi-Well Structure and Cell Distribution. The macroscopic features of the different bottom layers were evaluated by stereomicroscope (Olympus SXZ10). Cell distribution into the construct and feasibility of cell seeding into the wells were evaluated 
a

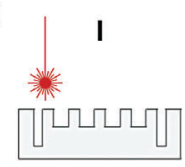

PMMA template

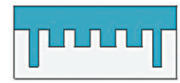

PDMS casting
III

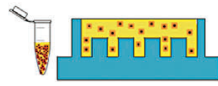

fibrin+cell casting (bottom layer)
IV

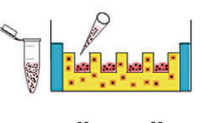

cell seeding
V

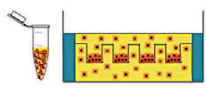

fibrin+cell casting (top layer)
VI

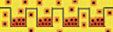

culture b

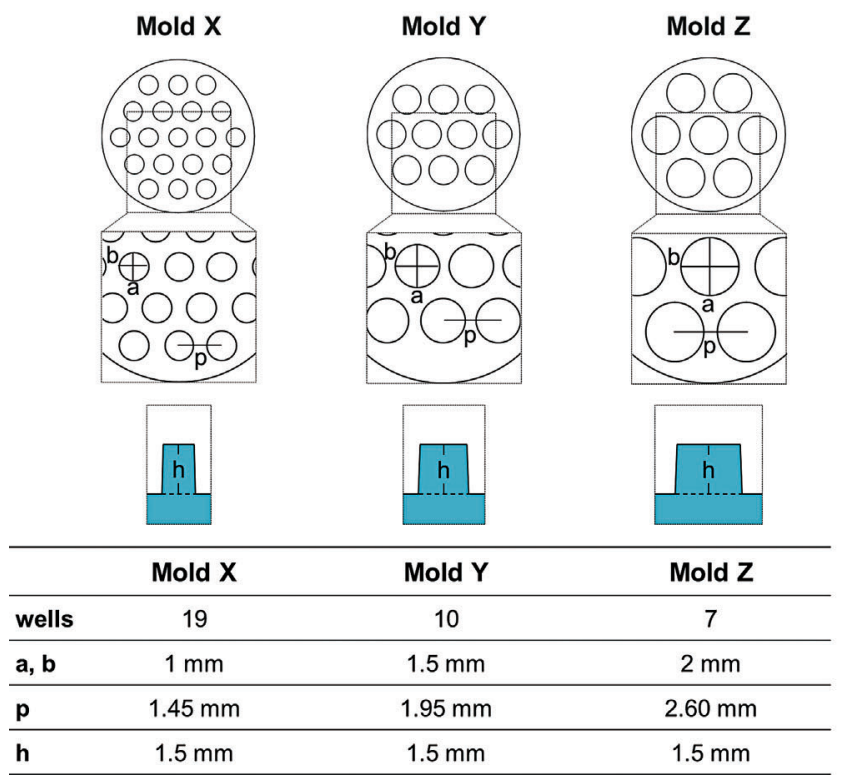

C

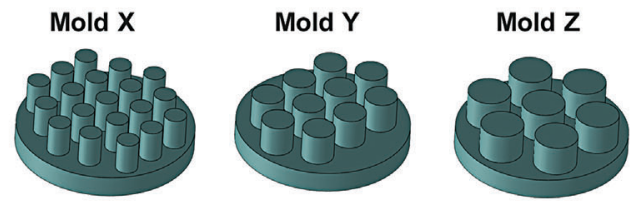

d

PMMA master templates

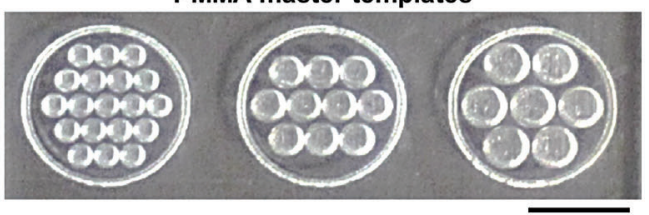

PDMS molds

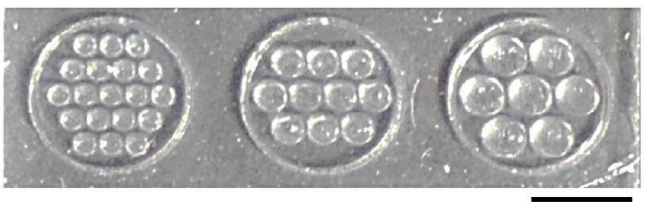

Figure 2. Biofabrication of implantable multi-well fibrin constructs. (a) Laser-ablated PMMA master templates (I) were used to generate PDMS counter-molds (II). Cells were mixed with fibrinogen and thrombin and poured into the PDMS mold to generate the multi-well bottom layer (III). After polymerization, the bottom layer was removed from the PDMS mold and cells were seeded in the wells of the construct (IV). A top layer made from cell-loaded fibrin was poured over the bottom layer to ultimate the scaffold (V). Medium was added for construct culture (VI). (b) CAD drawing including top view with insets showing diameter, pitch, and height of the pillars. Corresponding values for the three mold configurations (Mold X, Mold Y, Mold Z) are indicated in table. (c) 3D rendering of the three PDMS mold configurations. (d) PMMA master templates and PDMS molds with the three different configurations fabricated by laser ablation and replica molding (scale bars $5 \mathrm{~mm}$ ).

by fluorescence microscopy (Olympus IX71) using green or red cells stained either with the green fluorescent dye Vybrant DiO or with the red fluorescent dye Vybrant CM-Dil (both from Invitrogen) according to the manufacturer's instructions. Briefly, after trypsinization, cells were suspended at a density of $1 \times 10^{6}$ cells/ $\mathrm{mL}$ in serum-free culture medium. Vybrant DiO or Vybrant CM-Dil was added to the cell suspension $(5 \mu \mathrm{L} / \mathrm{mL})$. Cells were incubated for $10 \mathrm{~min}$ at $37^{\circ} \mathrm{C}$ and then centrifuged $(350 \mathrm{~g}, 5 \mathrm{~min})$. The supernatant was removed and the cells were washed twice in expansion medium prior to use.

Histological Analysis. After 7 days of in vitro culture, fibrin constructs cultured for 7 days were fixed for $24 \mathrm{~h}$ in $10 \%$ neutral buffered formalin, embedded in paraffin, and sectioned at $3 \mu \mathrm{m}$. For morphological evaluation of fibrin glue constructs, sections were stained with hematoxylin and eosin (HE).

Quantification of DNA and GAGs Content. After 7 days of in vitro culture, fibrin constructs were digested, as previously described for chondrocyte spheroids. DNA quantification was performed by CyQUANT Kit. The amount of GAGs was spectrophotometrically measured using $16 \mathrm{mg} / \mathrm{mL}$ dimethylmethylene blue (SigmaAldrich), with chondroitin sulphate as standard (absorbance $525 \mathrm{~nm}$ ) [Lopa et al., 2014]. GAGs content was normalized to the DNA content and expressed as $\mu \mathrm{g}$ GAGs/ $\mu \mathrm{g}$ DNA.

Gene Expression Analysis. After 1 and 7 days of in vitro culture, fibrin constructs were harvested and stored in liquid nitrogen for RNA isolation and gene expression analysis. Total RNA was purified using RNeasy Mini kit (Qiagen Inc., Valencia, CA) following sample disruption with TissueRuptor (Qiagen Inc.). RNA was quantified using a spectrophotometer (Nanodrop, Thermo Scientific, Waltham, MA) and reverse-transcribed to cDNA using iScript cDNA Synthesis Kit (Bio-Rad Laboratories, Hercules, CA). Gene expression was evaluated by real-time PCR (StepOne Plus, Life Technologies, Carlsbad, CA). Forty nanograms of cDNA were incubated with a PCR mixture, including TaqMan ${ }^{\mathbb{R}}$ Universal PCR Master Mix and TaqMan $^{\circledR}$ Assays-on-Demand ${ }^{\mathrm{TM}}$ Gene expression probes (Life 
Technologies) using the following assays: glyceraldehyde-3-phosphate dehydrogenase (GAPDH, Hs99999905_m1), SRY (Sex determining region Y)-box9 (SOX9, Hs00165814_m1), collagen type II alpha I (COL2A1, Hs00264051_m1), aggrecan (ACAN, Hs00153936_m1), and cartilage oligomeric matrix protein (COMP, Hs00164359_m1) The expression of the analyzed markers was normalized to GAPDH using the delta Ct method.

\section{Subcutaneous Implantation of Fibrin Constructs in Nude Mice}

Fibrin constructs without or with wells were seeded with green- and red-stained cells and subcutaneously implanted in nude mice. The in vivo study was approved by the Mario Negri Institute for Pharmacological Research (IRFMN) Animal Care and Use Committee (IACUC). Animals and their care were handled in compliance with institutional guidelines as defined in national (Law 116/92, Authorization n.19/2008-A issued March 6, 2008, Italian Ministry of Health) and international laws and policies (EEC Council Directive 86/609, OJ L 358. 1, December 12, 1987 Standards for the Care and Use of Laboratory Animals - UCLA, US National Research Council, Statement of Compliance A5023-01, November 6, 1998).

Three 6-week-old female athymic mice were obtained from Harlan ${ }^{\circledR}$ and maintained in the Animal Care Facilities of the IRFMN, under specific pathogen-free conditions with food and water provided ad libitum. Animals were anesthetized by intraperitoneal injection of ketamine chloride $(80 \mathrm{mg} / \mathrm{kg}$, Imalgene, Merial, Lyon, France) and medetomidine hydrochloride (1 mg/kg, Domitor, Pfizer, New York, NY). Surgical procedures were performed in sterile conditions under a laminar flow hood. Four subcutaneous pockets were created on the dorsum of each mouse by blunt dissection through cranial and caudal skin incisions. One fibrin construct was inserted in each pocket, then the skin was sutured with \#4-0 Monocryl thread (Ethicon, Somerville, NJ). After 5 weeks, mice were euthanized by $\mathrm{CO}_{2}$ inhalation and constructs were explanted.

\section{Explant Analysis}

Evaluation of Cell Distribution. After 5 weeks in vivo, the distribution of green- and red-stained cells in the explants was evaluated by fluorescent microscopy (Olympus IX71).

Quantification of GAGs Content. Fibrin constructs cultured in vitro for 7 days were analyzed before and after in vivo subcutaneous implantation for 5 weeks. Samples were digested in PBE buffer and GAGs were quantified by dimethylmethylene blue assay, as aforementioned. GAGs content was normalized to the construct wet weight (mg).

\section{Statistical Analysis}

All data are presented as mean \pm SD. Kolmogorov-Smirnov test was used to assess the normal data distribution (GraphPad Prism version 5.00 for Windows, GraphPad Software, San Diego, CA). For spheroid analysis, comparison among the three different experimental groups (control spheroids, spheroids in chip A, spheroids in chip B) was performed by One-Way ANOVA with Dunnett's post hoc test. Mann-Whitney test (unpaired data) for non-normally distributed data was performed to compare different types of fibrin constructs at the same time point (i.e., w/ wells $1 \mathrm{~d}$ vs. w/o wells $1 \mathrm{~d}$ ) and to compare the same type of fibrin construct at different time points (i.e., w/ wells $1 \mathrm{~d}$ vs. w/ wells $7 \mathrm{~d}$ ).

\section{Results}

\section{Multi-Well PDMS Chips Support the Generation and Culture of Chondrocyte Spheroids}

Multi-well chips were generated by PDMS replica molding on a laser-ablated PMMA master templates. Optical images of the fabricated multi-well PDMS chips in Figure 1d show the fidelity of the multi-well arrays to the original design. As expected, the side view of the PDMS chips section revealed the conical shape of the wells (Fig. 1d, bottom panel).

Articular chondrocytes were used to validate the multi-well PDMS chips as devices for the formation and culture of 3D cell spheroids. The PDMS chips were designed to fit the wells of a 12well multiwell plate, allowing the simultaneous culture of several spheroids in different experimental conditions in the same plate, as shown in Figure 3a, where PDMS chips immediately after cell seeding are depicted. The use of these devices significantly reduced the time required for cell seeding and medium refresh operations compared to standard spheroid culture, representing a technical amelioration in terms of work efficiency (Fig. 3b and c). The PDMS chips, thanks to the transparency of the material, also allowed us to monitor the samples through microscopy over the entire period of culture and to measure basic parameters, such as spheroid area. As shown in Figure 3d, cell aggregates started to form already $24 \mathrm{~h}$ after cell seeding and, after 21 days of culture, spheroids were wellformed in both PDMS chips. Spheroid area increased from 7 to 21 days of chondrogenic culture (Fig. 3e). At the end of culture, the metabolic activity, the DNA content, and the metabolic activity normalized on DNA of spheroids cultured in standard tubes (Ctrl) and in PDMS chips did not differ, showing that spheroids cultured in PDMS chips were at least as viable and active standard spheroids (Fig. 3f-h). Histological evaluation revealed that GAGs deposition, which is a key marker of chondrogenic differentiation, was comparable in Ctrl spheroids and in spheroids cultured in multiwell PDMS chips (Fig. 3i). Lacunar structures, similar to those found in native hyaline cartilage, were observed in all the experimental groups. Analysis of type II collagen deposition by immunohistochemistry displayed a more intense staining in spheroids cultured in PDMS chips compared to standard spheroids, indicating the production of highly specialized extracellular matrix in these samples (Fig. 3j).

\section{Implantable Multi-Well Fibrin Constructs With High Cell Density Regions Support the 3D Culture of Articular Chondrocytes}

Multi-well fibrin glue constructs were prepared according to the scheme in Figure 2a. The simplicity of the biofabrication process allowed us to prepare 65 multi-well constructs in a single 
a

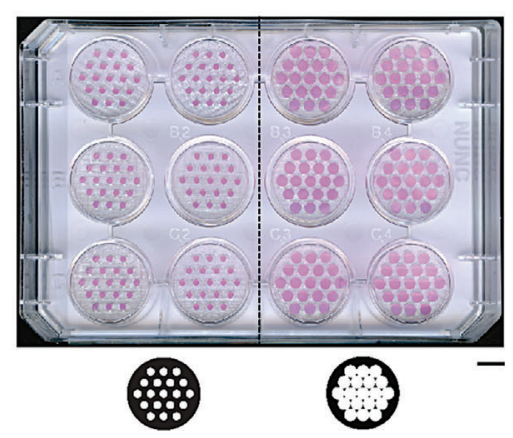

d

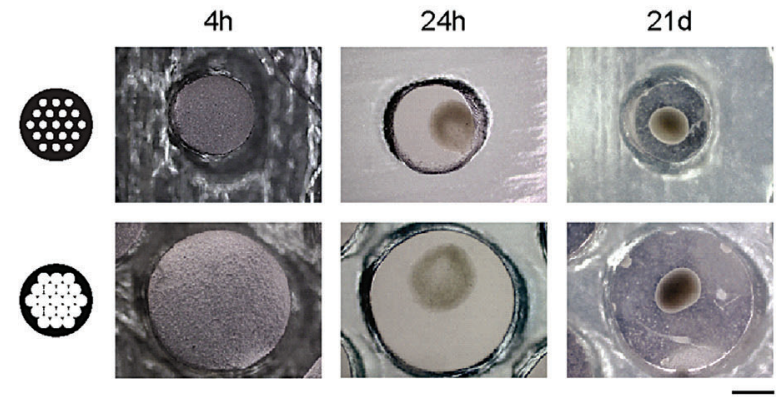

b

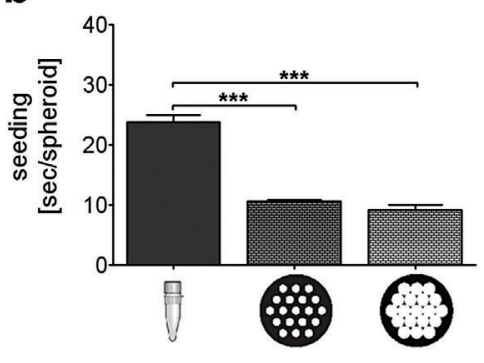

C

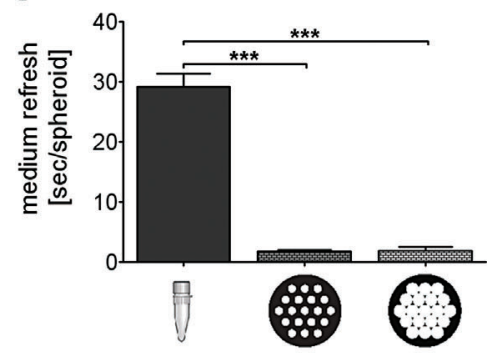

e

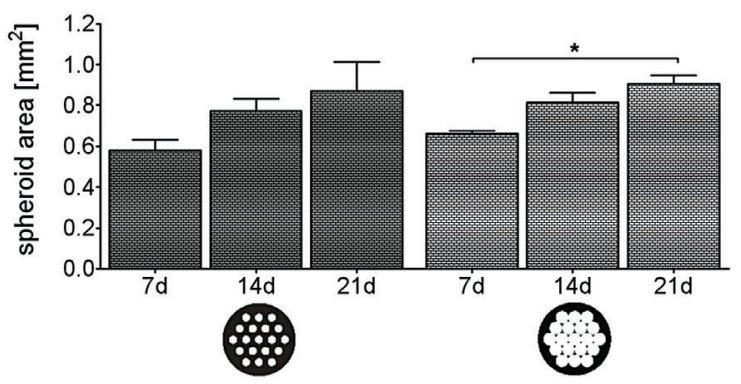

f

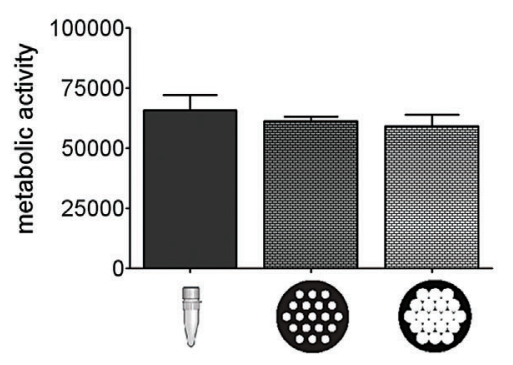

g

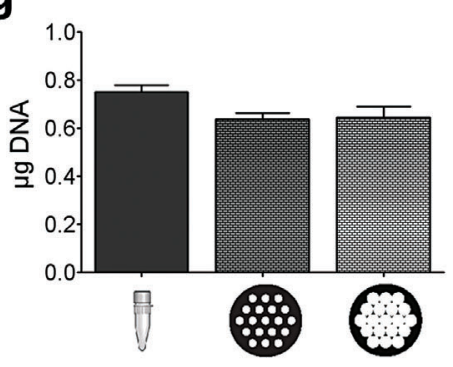

h

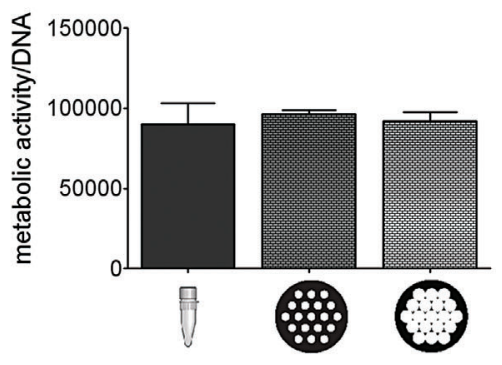

i
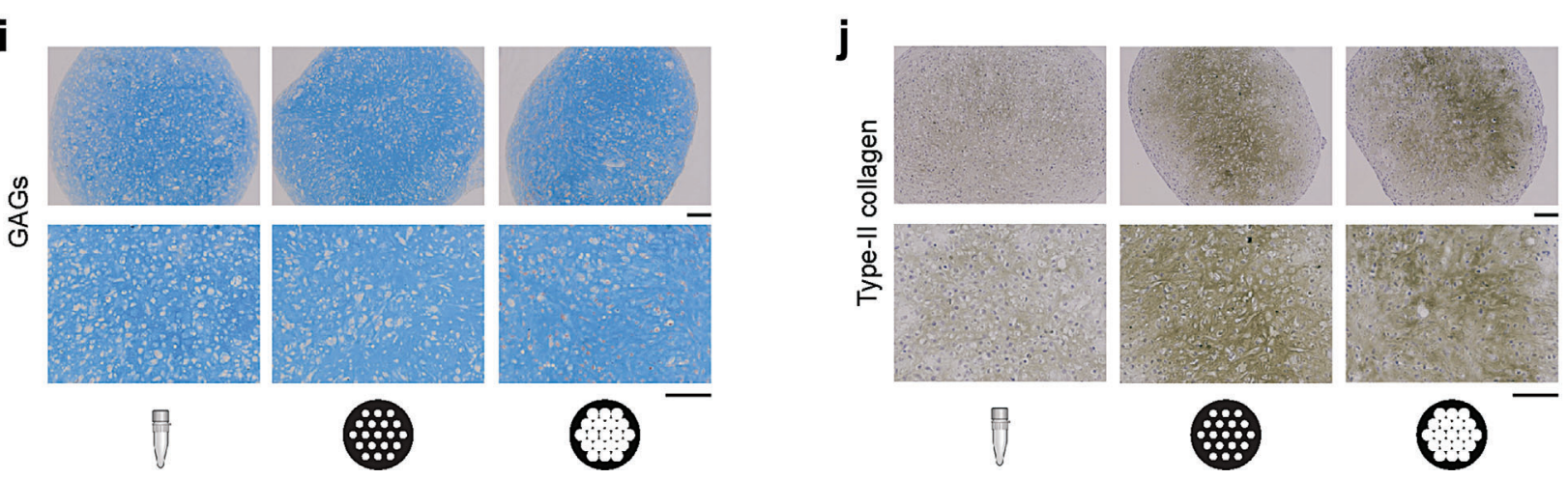

Figure 3. Validation of multi-well PDMS chips for formation and culture of cell spheroids. (a) Scan of a 12 well multiwell plate containing PDMS multi-well chips after cell seeding (scale bar $10 \mathrm{~mm})$. (b,c) Measurements of the operation time required to perform cell seeding and medium refresh. (d) Micrographs of a representative well of chip $A$ and chip B at different time points after cell seeding $(4 \mathrm{~h}, 24 \mathrm{~h}, 21$ days, scale bar $1 \mathrm{~mm})$. (e) Average area of spheroids cultured in Chip A and Chip B over time ( $n=54$, data obtained from three independent chips both for configuration A and B). (f-h) Metabolic activity, DNA content, and metabolic activity normalized on DNA content measured in spheroids cultured for 21 days in standard conditions $(n=9)$ or in PDMS chips $(n=9$, nine samples harvested from three independent chips both for configuration A and B). (i,j) Histological evaluation of GAGs and type II collagen deposition in spheroids cultured for 21 days in standard conditions and in PDMS chips (scale bars $200 \mu \mathrm{m}$ ). 
a

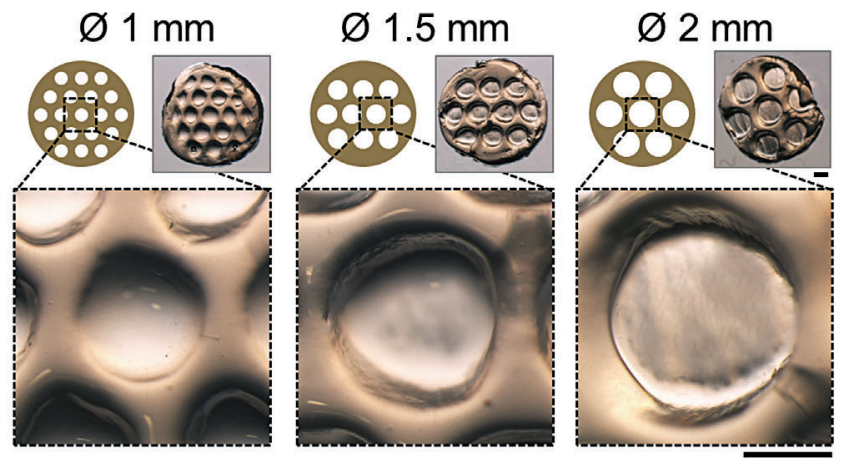

b
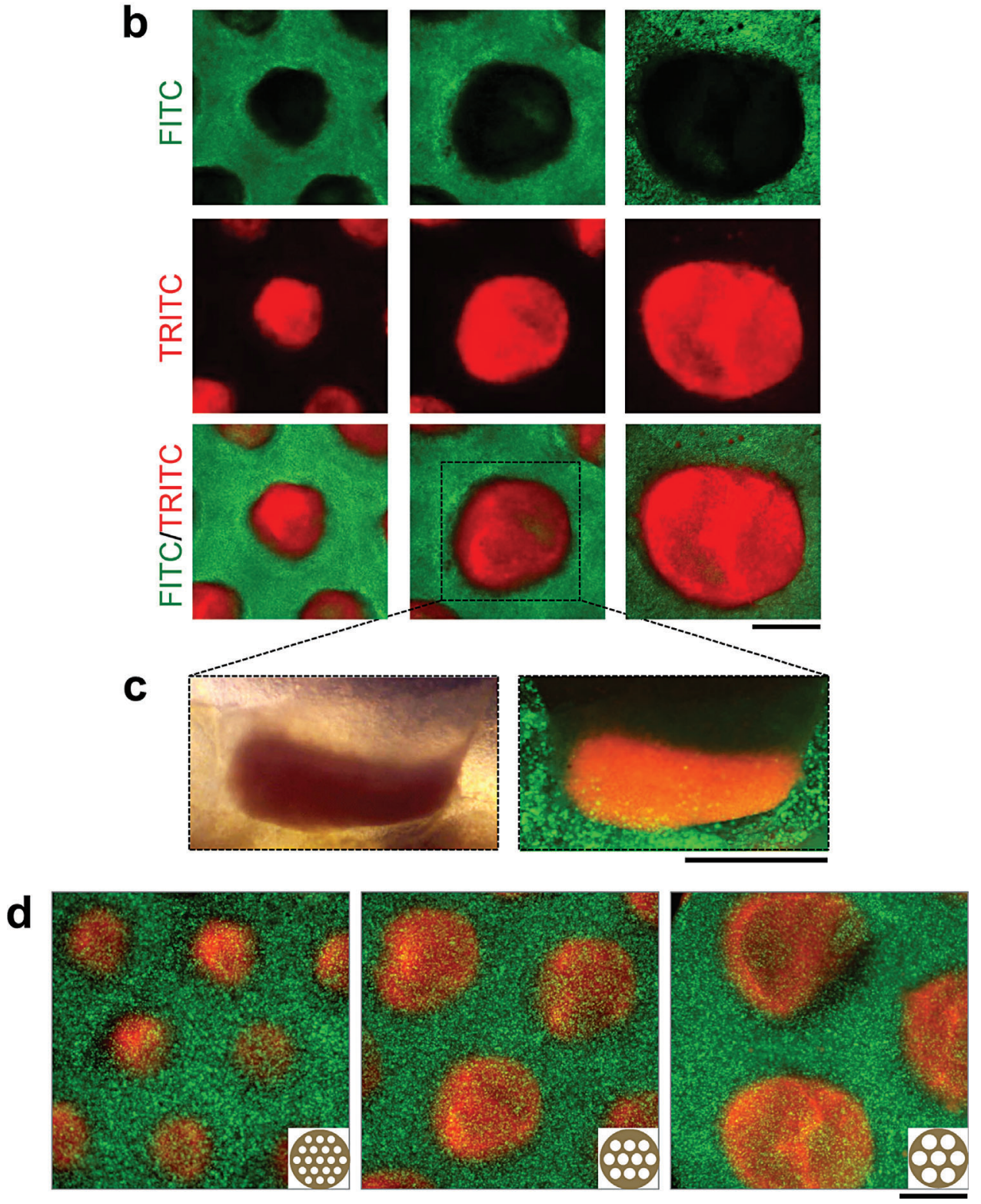

Figure 4. Fabrication of multi-well fibrin constructs and evaluation of cell distribution. (a) Design and stereomicroscope micrographs showing the three different bottom layer configurations (scale bars $1 \mathrm{~mm}$ ). (b) Micrographs showing cell distribution in the multi-well fibrin constructs. Green-stained cells are embedded into the bottom layer, whereas redstained cells are seeded into the wells (scale bar $1 \mathrm{~mm}$ ). (c) Micrographs showing the central section of a cell-seeded fibrin constructs $\left(\oslash_{\text {well }} 1.5 \mathrm{~mm}, \mathrm{~h} 1.5 \mathrm{~mm}\right.$, phase contrast and fluorescence microscopy, scale bar $1 \mathrm{~mm}$ ). (d) Micrographs showing the multi-well pattern in the construct after the top layer polymerization. Green-stained cells are embedded into bottom and top layer and red-stained cells are seeded into the wells (scale bar $1 \mathrm{~mm}$ ). 
experimental run. PMMA master templates and PDMS molds with the three different configurations $(\mathrm{X}, \mathrm{Y}, \mathrm{Z}$ ) were used to generate the corresponding bottom layers (Fig. 4a). We noticed that the configuration with 10 wells $\left(\oslash_{\text {well }} 1.5 \mathrm{~mm}\right.$ ) was the easiest to fabricate and handle. Indeed, the configuration with larger wells ( $\oslash_{\text {well }} 2 \mathrm{~mm}$ ) had a very thin outer border that did not allow for the easy removal of the construct from the PDMS mold. The peripheral border of these constructs tended to break during this operation (Fig. 4a, upper row), resulting in leaking of the seeded cells into the adjacent wells. On the other hand, the configuration with smaller wells ( $\oslash_{\text {well }} 1 \mathrm{~mm}$ ) was quite easy to manipulate since stiffer, but small imperfections in the fibrin bottom layer resulted in a dramatic reduction of the volume of the wells (Fig. 4a, upper row), which challenged the reproducibility of cell seeding. Cell embedding in the bottom layer resulted in a homogeneous cell distribution (Fig. 4b, upper row, green-stained cells) and cell seeding in the multi-wells proved also to be effective (Fig. 4b, middle and lower row). Based on the aforementioned considerations about simplicity and reproducibility of fabrication, we selected the configuration (Y) with 10 wells ( $\oslash_{\text {well }} 1.5 \mathrm{~mm}, \mathrm{~h}_{\text {well }} 1.5 \mathrm{~mm}$ ) for the prosecution of the study. The central section of the bottom layer shows the cell deposition on the bottom side of each well (Fig. 4c), demonstrating that redstained cells were confined into the wells and that we were able to generate regions with different cell density in a single construct. The multi-well constructs were completed by adding the top layer, as shown in Figure 4d, where the multi-well array in the finalized scaffold can be observed.

In Figure 5a, macroscopic pictures of fibrin constructs without and with wells after top layer polymerization are reported. The pattern of multi-well, visible through the fibrin top layer, is highlighted by the dotted lines in half construct (Fig. 5a, right image). In fibrin constructs without wells, cells were homogeneously distributed throughout the entire scaffold (Fig. 5b and c, left image). In contrast, in multi-well constructs, single wells were clearly visible and hematoxylin/eosin staining showed that a cell multi-layer was present in the wells (Fig. $5 \mathrm{~b}$ and c, right image), demonstrating once again that different cell density areas were generated in the construct. As revealed by histological analysis, poor matrix deposition and construct remodeling occurred after 7 days of in vitro culture (Fig. 5c), probably due to the high concentration of fibrinogen used in our constructs as well as to the short period of in vitro culture.

After 7 days of culture in chondrogenic medium, the same number of cells was found in standard fibrin constructs and in multi-well constructs (Fig. 5d) and no significant difference in terms of GAGs content was observed between the two fibrin constructs (Fig. 5e). Gene expression analysis performed after 1 and 7 days of culture in chondrogenic medium revealed that both types of fibrin constructs well supported chondrocyte culture. We observed that levels of chondrogenic markers, such as SOX9, COL2A1, ACAN, and COMP, increased from day 1 to day 7 , with significant differences between time points for all the analyzed markers with the exception of SOX9 (Fig. 5f-i). Higher transcriptional levels of all the tested markers were measured in ACs cultured in fibrin constructs with high cell density regions for 7 days, albeit increases with respect to constructs without wells were not significantly different (Fig. 5f-i).
Finally, we evaluated the in vivo behavior of ACs in fibrin constructs without or with wells through subcutaneous implantation in nude mice. After 5 weeks of implantation, construct size was dramatically reduced. The pictures reported in Figure 6a represent the same constructs imaged before and after in vivo implantation with the same microscope magnification, clearly showing the diameter reduction from $8 \mathrm{~mm}$ to $1.5-2 \mathrm{~mm}$. Surprisingly, despite the reduction in construct size, the multi-well structure was maintained, as shown in the post-implantation pictures where the high cell density areas corresponding to the wells are still visible. GAGs content was evaluated in the fibrin constructs cultured in vitro for 7 days (pre-implantation) and in the explants harvested after 5 weeks of subcutaneous implantation (post-implantation). The content of GAGs normalized on construct wet weight was found to be significantly increased in both types of fibrin constructs after 5 weeks in vivo compared to pre-implantation samples. No significant differences between the two types of fibrin constructs was observed at any time point (Fig. 6b).

\section{Discussion}

The primary purpose of this study was to generate multi-well PDMS chips supporting the formation and culture of cell spheroids and to biofabricate a multi-well fibrin construct through low-cost and easily accessible rapid prototyping techniques.

Compared to standard protocols, the use of the PDMS multi-well chips significantly reduced the operation time for cell seeding and medium refresh, which are highly time-consuming factors when preparing several replicates for many experimental groups. The possibility to culture simultaneously a maximum of 228 cell spheroids in a single 12-well multiwell plate also reduced the space required for the culture of such a high number of samples in the $\mathrm{CO}_{2}$ incubator. Furthermore, the optical transparency of the PDMS chips allowed us to monitor the process of spheroid formation and the increase in spheroid area occurring during culture. Considering a starting DNA content of $1.155 \mu \mathrm{g}$ DNA/spheroid, based on $7.7 \mathrm{pg}$ DNA/chondrocyte [Kim et al., 1988] and $1 \times 10^{5}$ chondrocyte/ spheroid, we observed a reduction in cell number in spheroids cultured for 21 days in PDMS chips. A similar reduction was observed in standard spheroids cultured in polypropylene tubes. This observation is coherent with literature data obtained for the chondrogenic 3D culture of mesenchymal stem cells and articular chondrocytes [Giovannini et al., 2010; Lopa et al., 2013] and indicates that the increase in spheroid area observed in our experiments over time was due to extracellular matrix deposition and not to cell proliferation.

The high hydrophobicity of PDMS [Berthier et al., 2012], related to the low cell adhesion on this material, led to the formation of well-defined chondrocyte spheroids in both the tested configurations. The comparison between spheroids generated and cultured in PDMS chips with spheroids in polypropylene tubes did not show any significant difference in terms of cell proliferation and metabolic activity. On the contrary, while deposition of GAGs was similar in the different experimental groups, type-II collagen was more present in spheroids cultured in the PDMS chips compared to standard spheroids. These results indicate that the multi-well devices were able to support very well both cell viability 

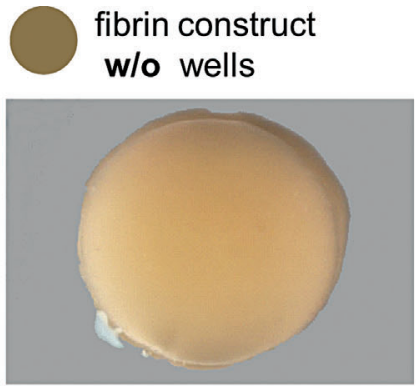

b

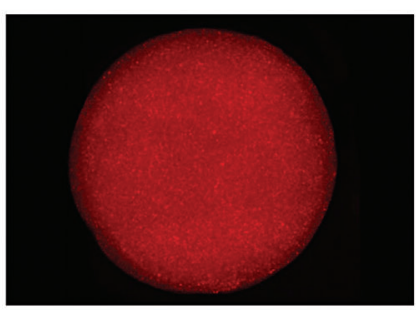

C

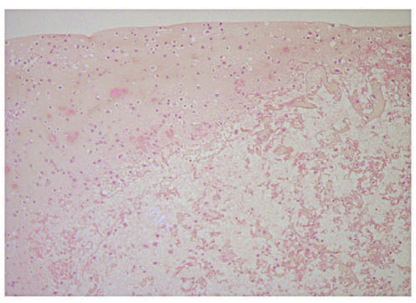

d

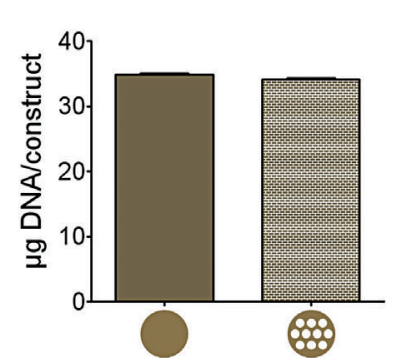

89 fibrin construct w/ wells
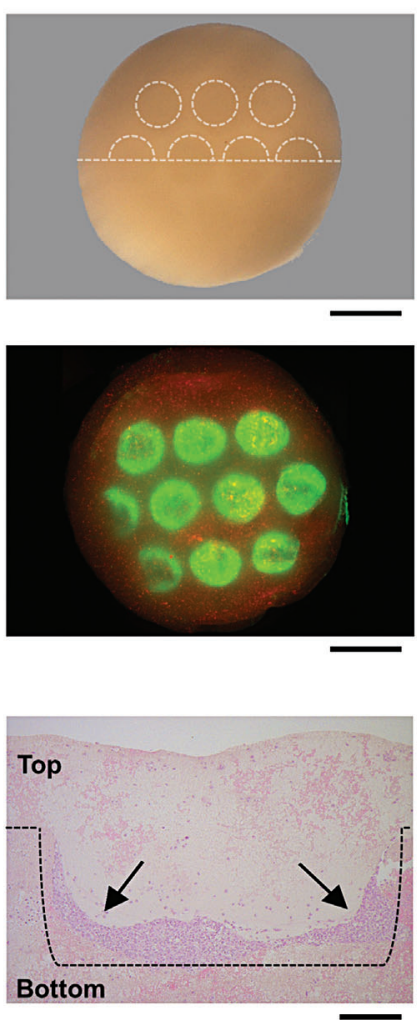

e

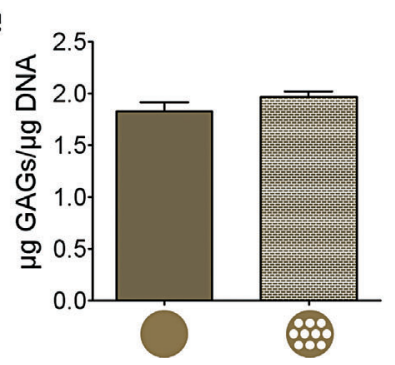

f

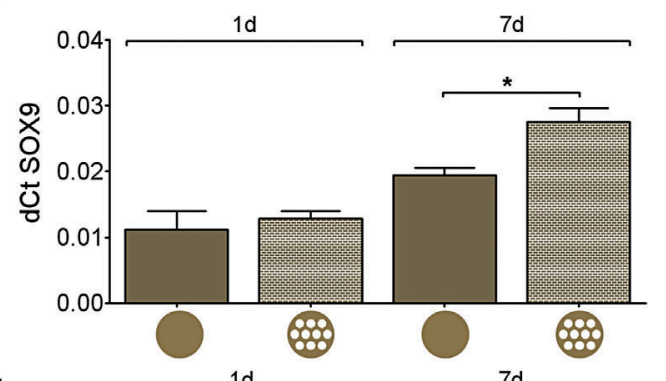

g

h
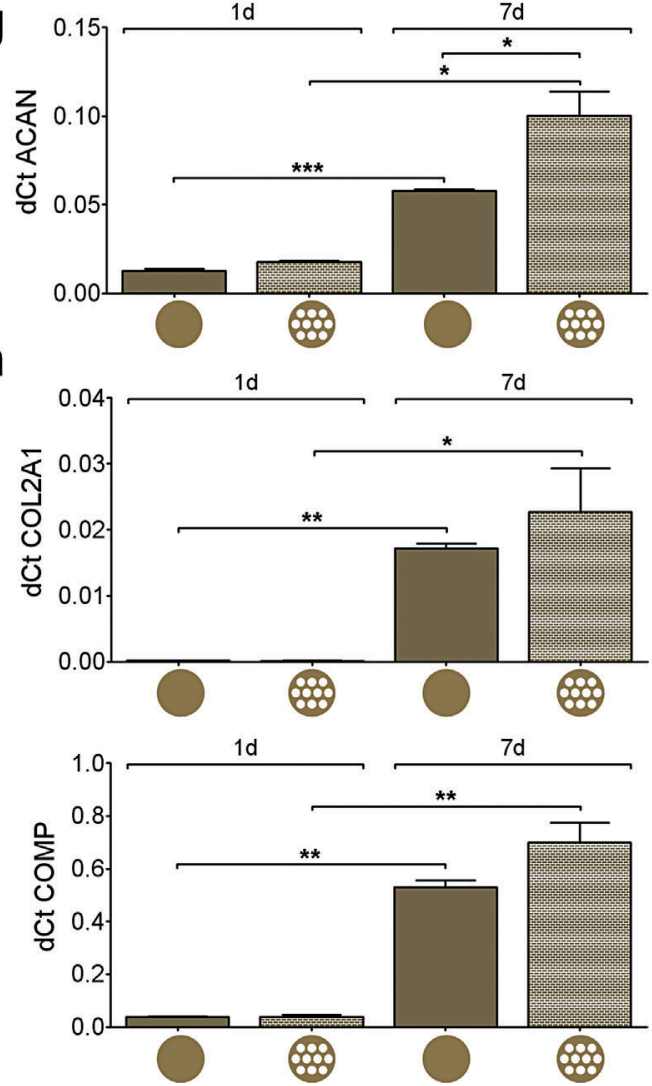

Figure 5. Comparison between standard and multi-well fibrin constructs. (a) Representative pictures of standard and multi-well fibrin constructs (scale bar 2 mm). Dotted lines highlight the multi-well pattern under the top layer in half construct. (b) Micrographs showing cell distribution in fibrin constructs w/o wells and w/ wells (scale bar $2 \mathrm{~mm}$ ). (c) Hematoxylin/eosin staining of construct sections. The border of the well are indicated by a dotted line and cells distributed along the lower border of the well are indicated by arrows (scale bar $200 \mu \mathrm{m}$ ). (d,e) DNA content and GAGs content normalized on DNA measured in fibrin constructs w/ and w/o wells after 7 days of in vitro culture $(n=3)$. ( $\mathbf{f}-\mathbf{i})$ Transcriptional levels of SOX9, COL2A1, ACAN, and COMP evaluated in fibrin constructs $w /$ and w/o wells after 1 and 7 days of in vitro culture ( $n=4)$. Gene expression data are normalized on $\mathrm{GAPDH}$ using the delta $\mathrm{Ct}(\mathrm{dCt})$ method.

and chondrogenic differentiation, thus representing an appealing option for 3D cell culture. A similar approach has been used in a very recent study to produce and culture chondrocyte micro-pellets (166 cells/pellet) by Babur et al. [Babur et al., 2013]. In their study, the PDMS insert surface had to be chemically modified to avoid cell spreading all over the well. By contrast, in our devices, the higher ratio between the number of plated cells and the surface available for cell growth overcame the need for any chemical surface treatment, since centrifugation was sufficient to trigger spheroid formation in the wells. Rapid prototyping of PDMS devices hold great potential for studies requiring the indirect co-culture of different cell types, as previously reported for hepatocytes and
Kupffer cells [Zinchenko and Coger, 2005]. In our system, the possibility to precisely seed each well with a specific cell population, together with the easiness of spheroid harvesting from selected wells, allows to evaluate the effect of paracrine factors in each cell type, representing a complementary alternative to the trans-well system where cells are traditionally cultured in monolayer. The high hydrophobicity and porosity of PDMS may cause the non-specific absorption/adsorption of small molecules [Toepke and Beebe, 2006], representing a potential bias when using PDMS devices for cell culture applications. In our study, to maintain stable cell culture conditions and to reduce the effects of non-specific absorption/adsorption in PDMS, we performed systematic 
a
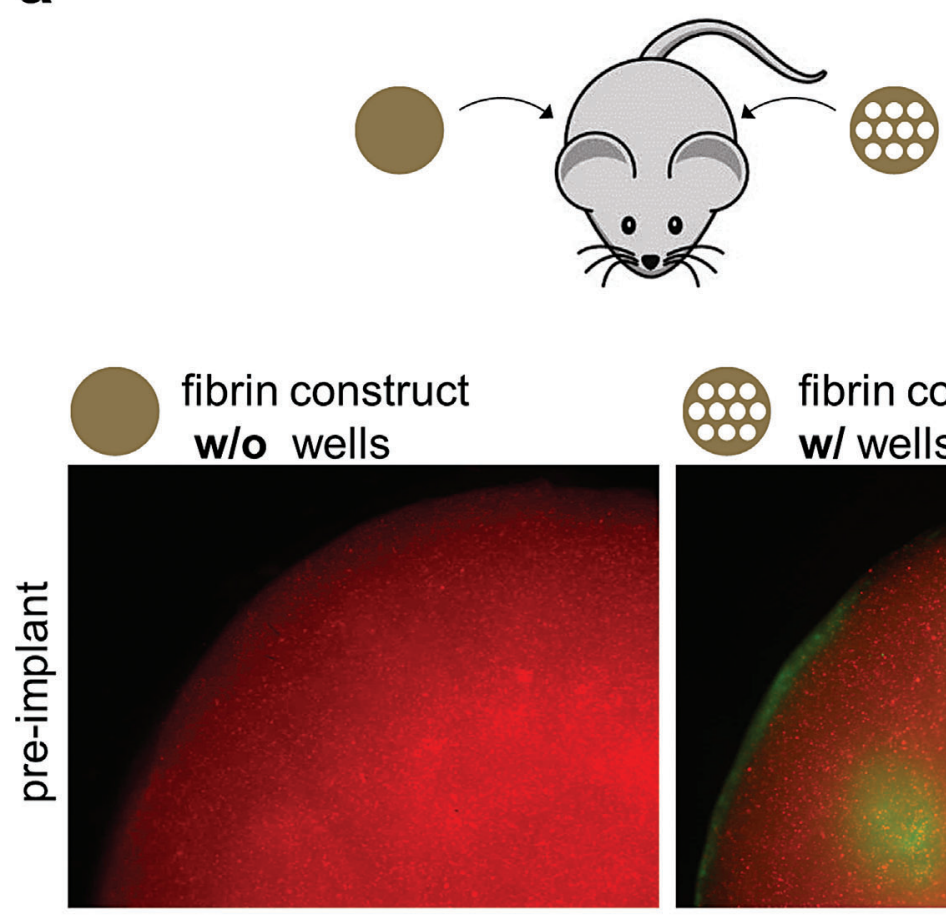

880 fibrin construct

w/ wells
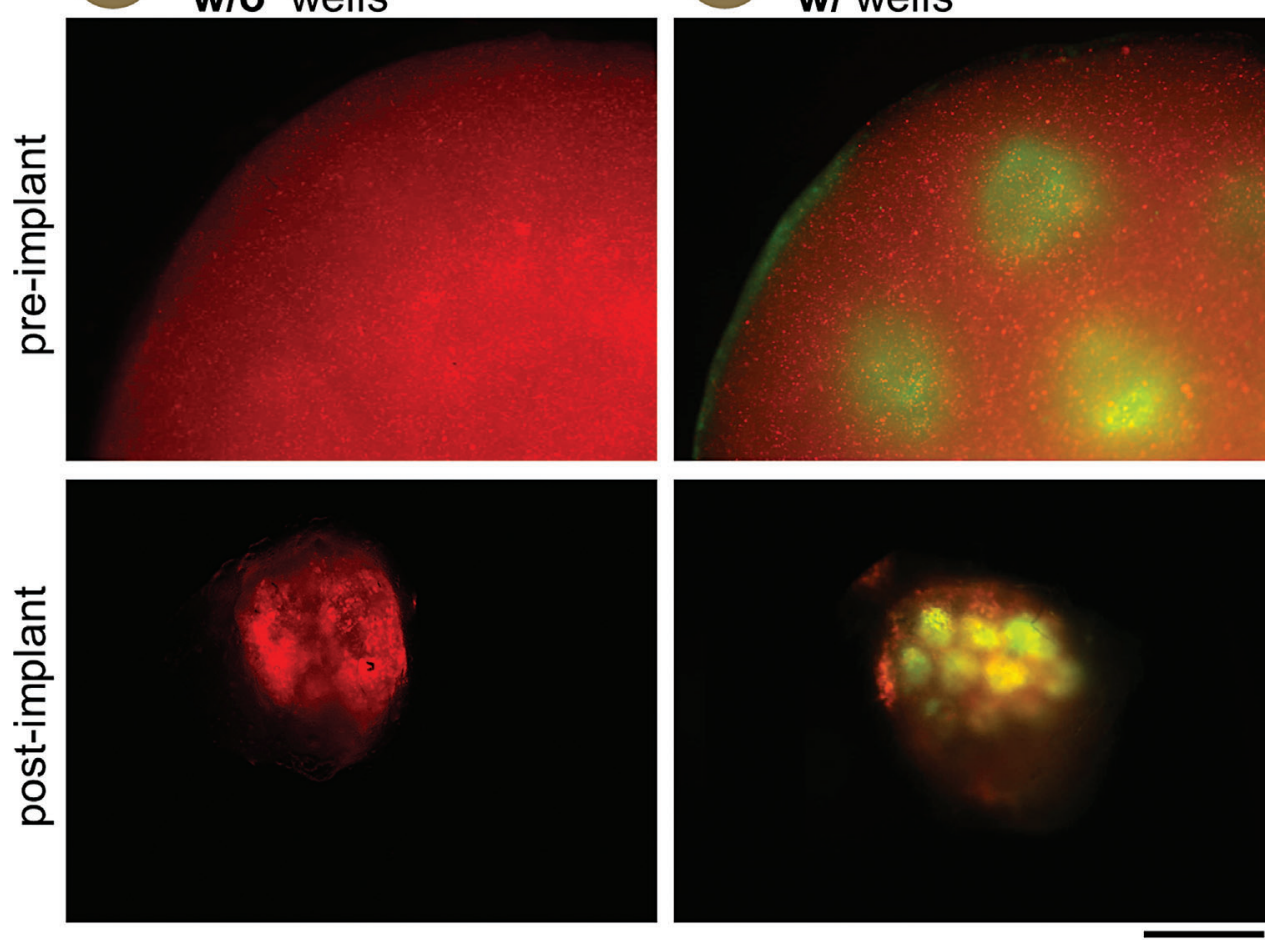

b

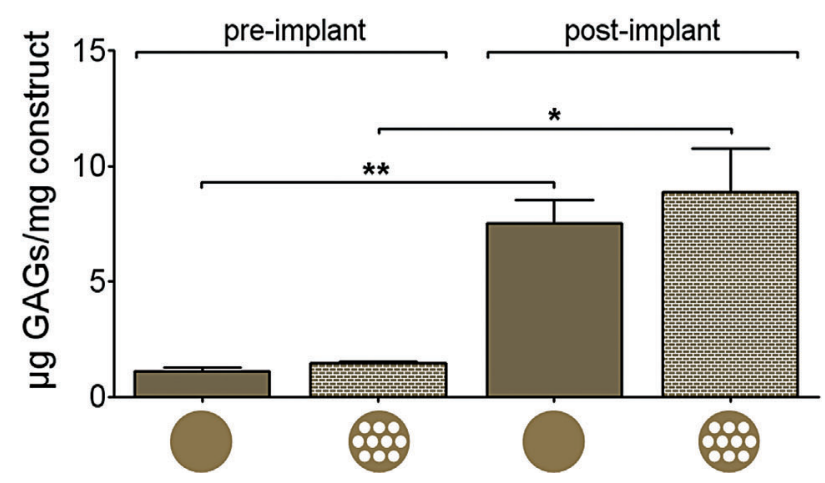

Figure 6. Cell distribution and GAGs content in fibrin constructs before and after in vivo implantation in nude mice. (a) Micrographs showing standard and multi-well fibrin constructs seeded with red and/or green stained cells before and after subcutaneous implantation in nude mice (scale bar $1 \mathrm{~mm}$ ). (b) GAGs content normalized on construct wet weight measured in fibrin constructs $w / 0$ and $w /$ wells before and after subcutaneous implantation $(n=3)$. 
replacement of culture medium. Indeed, we did not observe any relevant effect on the metabolic activity and chondrogenic redifferentiation in ACs spheroids cultured in our multi-well PDMS chips compared to spheroids in standard polypropylene tubes. However, to minimize possible biological bias, which may be particularly relevant in studies evaluating the paracrine interaction between multiple cell types, treatments developed to prevent nonspecific molecule absorption/adsorption in PDMS could also be applied [Gomez-Sjoberg et al., 2010; Harris et al., 2011; Huang et al., 2005]. Besides applications in basic research investigating the mutual influence between different cell types, multi-well PDMS chips can be used to produce a high number of mini-tissue spheroids, which represent the building blocks in organ printing approaches [Boland et al., 2003; Jakab et al., 2004; Mironov et al., 2009]. Indeed, we found that spheroids were viable and metabolically active after a relatively long culture period. Furthermore, histological evaluation showed that cells were able to produce specific extracellular matrix. Finally, considering the field of cartilage tissue engineering, the low-cost multi-well PDMS chips described here could be exploited to generate a high number of autologous 3D chondral spheroids to be used in the treatment of chondral defects, as proposed by a recent clinical trial (http:// clinicaltrials.gov/, NCT01222559).

In the past years, different approaches have been developed to generate and culture 3D cell spheroids. Cell spheroids have been generated combining the actions of fluid flow and gravity force in microfluidic devices [Fu et al., 2014; Patra et al., 2013; Piraino et al., 2012a] or exploiting gravity-enforced cell assembly in manual [Cavnar et al., 2014; Tung et al., 2011] and automated cell dispensing systems [Xu et al., 2011]. A preliminary optimization phase, more or less extensive depending on the system complexity, is, however, required for all these approaches. Here, to generate cell spheroids we employed multi-well PDMS chips fabricated by lowcost rapid prototyping techniques. Remarkably, our system takes advantage of centrifugal force to promote cell assembly in 3D spheroids, exploiting the same strategy used to generate cell spheroids in polypropylene tubes and hence allowing for the streamlined and direct translation of standard protocols.

In the second part of the study, we applied the same rapid prototyping techniques to produce a multi-well implantable fibrin construct. Considering the field of cartilage tissue engineering, we suggest that a similar configuration can be used to generate high cell density areas within the construct, leading to the formation of "chondrogenic centers" able to promote the differentiation of low cell density regions. Indeed, it has been shown that cell density affects the capability of chondrocytes to produce specific matrix and that a high cell density improves cartilaginous matrix deposition in 3D scaffolds [Mauck et al., 2003; Talukdar et al., 2011]. Since cartilage biopsies harvestable from patients are limited in size and allow the retrieval of a limited number of chondrocytes, an extensive in vitro expansion phase is required to obtain enough cells to seed a 3D scaffold with a high cell density, which implies chondrocyte de-differentiation [Giannoni and Cancedda, 2006; Giannoni et al., 2005; Schulze-Tanzil, 2009; Steinert et al., 2007]. The possibility of limiting the high cell density to some construct regions, acting as "chondrogenic centers", implies a reduction in the number of cells required to seed the construct, and subsequently a shorter expansion phase and a lower impact of cell dedifferentiation. Similar approaches have been proposed by other groups that have used chondrocytes aggregates of different dimensions seeded either in a collagen porous scaffold [Wolf et al., 2008] or embedded in a hydrogel [Moreira Teixeira et al., 2012]. Here, we did not generate the chondrocyte aggregate before, but high cell density centers were represented by confluent cell multilayers within the wells. We found that fibrin constructs supported the 3D culture of articular chondrocytes, as demonstrated by gene expression analysis over time. Furthermore, we found that the presence of high cell density regions in the fibrin constructs improved the transcriptional expression of chondrogenic markers. Indeed, in multi-well fibrin constructs we measured higher levels of SOX9 and $A C A N$, which encode respectively for a transcriptional factor modulating the chondrogenic cascade and for one of the major components of cartilaginous extracellular matrix, supporting the hypothesis that high cell density regions may act as chondrogenic centers. However, the short period of in vitro culture did not allow us to appreciate possible differences in terms of extracellular matrix deposition between standard and multi-well constructs.

Remarkably, the construct configurations proposed in this study also offer the flexibility to be seeded with pre-formed cell aggregates where desired, because the dimensions of the wells are compatible with those of chondrocyte spheroids obtained through standard techniques ( $\oslash 0.5-2 \mathrm{~mm}$ ). In this case, the use of multi-well constructs described here would allow for the controlled distribution of cell aggregates, which cannot be achieved through a randomized seeding.

As hypothesized for the PDMS chips, the multi-well construct produced in this study can be used for the co-culture of different cell types, which is usually performed by more standard 3D models, such as spheroids [Giovannini et al., 2010; Lopa et al., 2013; Wu et al., 2012] and random cell dispersion in 3D scaffolds [Hildner et al., 2009; Sabatino et al., 2012]. The controlled distribution of mesenchymal stem cells and bovine chondrocytes in an implantable multi-well scaffold has been performed in a recent study screening the effect of several extracellular matrix components on the chondrogenesis of MSCs co-cultured with bovine chondrocytes [Higuera et al., 2013]. Differently from this screening platform, where a polymeric scaffold is used and cells are seeded uniquely into the wells [Higuera et al., 2013], in our fibrin multi-well construct cells can be seeded both into the construct structure and in the wells, further allowing for the evaluation of the interactions between multiple cell types distributed in different construct regions.

Bioprinting techniques could also be exploited to control cell distribution in 3D fibrin constructs [Cui and Boland, 2009] and to generate constructs seeded with multiple cell types [Kolesky et al., 2014; Schuurman et al., 2011]. As demonstrated by several studies employing bioprinting to generate complex 3D structures, this approach allows an extremely precise control over construct configuration and cell distribution [Murphy and Atala, 2014]. However, differently from the simple biofabrication method that we have presented here, the use of bioprinting approaches implies higher costs related both to the bioprinter apparatus. Moreover, a relevant and time-consuming optimization phase is required to obtain the desired construct configuration, as well as proper cell distribution and viability. 
Regarding the behavior of fibrin constructs in vivo, we observed a dramatic size reduction of the implants after 5 weeks of subcutaneous implantation. This result has been previously reported in several short-term in vivo studies [Colombini et al., 2014b; Hwang et al., 2013; Peretti et al., 2000] and can be explained by two major features of fibrin: its fast degradation rate and its tendency to shrink upon cell culture [Ahmed et al., 2008; Meinhart et al., 1999; Wolbank et al., 2014]. We found that the implant size reduction did not alter cell distribution pattern in the multi-well constructs. Indeed dispersed red-stained cells and green-stained spots corresponding to the high cell density regions were clearly visible before and after subcutaneous implantation. On the other hand, when fibrin constructs were cultured in vitro for 7 days, we observed a poor construct remodeling, meaning that the multi-well structure was well preserved and that cells were not able to deposit a relevant amount of extracellular matrix. These observations can be explained by the short period of in vitro culture applied, sufficient to reveal an increase in the transcriptional expression of chondrogenic genes, but not a relevant deposition of matrix proteins. The concentrations of fibrinogen and thrombin used to prepare different fibrin formulations are known to affect cell behavior, including cell proliferation, cell elongation, and cell differentiation [Bensaid et al., 2003; Catelas et al., 2006; Cox et al., 2004]. In particular, it has been shown that, on equal thrombin concentration, increasing fibrinogen concentrations correlate with a reduction in pore size and with an increase in compressive modulus of fibrin gels [Blomback et al., 1994; Mooney et al., 2010; Roberts et al., 1974]. Furthermore, fibrinogen concentration is a major determining factor in fibrin degradation, with formulations with high fibrinogen concentrations $(25-50 \mathrm{mg} /$ $\mathrm{mL}$ ) being degraded more slowly compared to the formulations with low fibrinogen concentrations $(5 \mathrm{mg} / \mathrm{mL})$ [Cox et al., 2004; Mooney et al., 2010]. Delayed fibrin remodeling and reduced extracellular matrix deposition have been observed in fibrin formulations with high matrix density and low degradation rate [Ahmann et al., 2010; Cox et al., 2004; Ghajar et al., 2008; Kniazeva et al., 2011]. These features are typical of the fibrin formulation used in our study, characterized by a high fibrinogen concentration and by the presence of aprotinin, which further stabilizes the fibrin network [Meinhart et al., 1999]. Hence, we hypothesize that the poor remodeling and extracellular matrix deposition observed after a short period of in vitro culture in our fibrin constructs are, at least partially, due to their high density and slow degradation rate which, in turn, depend on the fibrin formulation used here. Since it has been shown that lower concentrations of fibrinogen are compatible with the biofabrication of patterned scaffolds [Koroleva et al., 2012], we envision tuning this parameter in future in vitro studies in order to favor the interaction of multiple cell types seeded in different construct regions, as well as extracellular matrix deposition.

\section{Conclusions}

We have presented a cost-effective method exploitable for the fabrication of platforms for the culture of multiple cell spheroids and for scaffold prototyping. Remarkably, the proposed fabrication approach is simple and exploits economic tools, such as commercial design software and desktop laser, which do not require dedicated facilities and can be accessible to most research laboratories. These features prompt the application of this approach in basic and translational research, whereby cell spheroids and 3D constructs represent key models in drug screening studies, as well as the building blocks for translational tissue engineering approaches.

This work was supported by the Italian Ministry of Health. The authors would like to acknowledge Alessandra Colombini, M.Sc. and Cristina Ceriani, M.Sc. for their precious help in the optimization of RNA isolation from fibrin constructs and in gene expression analysis.

\section{References}

Abbott A. 2003. Cell culture: Biology's new dimension. Nature 424(6951):870-872. Ahmann KA, Weinbaum JS, Johnson SL, Tranquillo RT. 2010. Fibrin degradation enhances vascular smooth muscle cell proliferation and matrix deposition in fibrin-based tissue constructs fabricated in vitro. Tissue Eng Part A 16(10):3261-3270.

Ahmed TA, Dare EV, Hincke M. 2008. Fibrin: A versatile scaffold for tissue engineering applications. Tissue Eng Part B Rev 14(2):199-215.

Ahmed TA, Hincke MT. 2010. Strategies for articular cartilage lesion repair and functional restoration. Tissue Eng Part B Rev 16(3):305-329.

Babur BK, Ghanavi P, Levett P, Lott WB, Klein T, Cooper-White JJ, Crawford R, Doran MR. 2013. The interplay between chondrocyte redifferentiation pellet size and oxygen concentration. PLoS One 8(3): 558865.

Bae CY, Min MK, Kim H, Park JK. 2014. Geometric effect of the hydrogel grid structure on in vitro formation of homogeneous MIN6 cell clusters. Lab Chip 14(13):2183-2190.

Becker H, Gartner C. 2008. Polymer microfabrication technologies for microfluidic systems. Anal Bioanal Chem 390(1):89-111.

Bensaid W, Triffitt JT, Blanchat C, Oudina K, Sedel L, Petite H. 2003. A biodegradable fibrin scaffold for mesenchymal stem cell transplantation. Biomaterials 24(14):2497-2502.

Bernstein P, Dong M, Corbeil D, Gelinsky M, Gunther KP, Fickert S. 2009. Pellet culture elicits superior chondrogenic redifferentiation than alginate-based systems. Biotechnol Prog 25(4):1146-1152.

Berthier E, Young EW, Beebe D. 2012. Engineers are from PDMS-land. Biologists are from Polystyrenia. 12(7):1224-1237.

Blomback B, Carlsson K, Fatah K, Hessel B, Procyk R. 1994. Fibrin in human plasma: gel architectures governed by rate and nature of fibrinogen activation. Thromb Res 75(5):521-538.

Boland T, Mironov V, Gutowska A, Roth EA, Markwald RR. 2003. Cell and organ printing 2: Fusion of cell aggregates in three-dimensional gels. Anat Rec A Discov Mol Cell Evol Biol 272(2):497-502.

Burdett E, Kasper FK, Mikos AG, Ludwig JA. 2010. Engineering tumors: A tissue engineering perspective in cancer biology. Tissue Eng Part B Rev 16(3): 351-359.

Catelas I, Sese N, Wu BM, Dunn JC, Helgerson S, Tawil B. 2006. Human mesenchymal stem cell proliferation and osteogenic differentiation in fibrin gels in vitro. Tissue Eng 12(8):2385-2396.

Cavnar SP, Salomonsson E, Luker KE, Luker GD, Takayama S. 2014. Transfer, imaging, and analysis plate for facile handling of 384 hanging drop 3D tissue spheroids. J Lab Autom 19(2):208-214.

Colombini A, Ceriani C, Banfi G, Brayda-Bruno M, Moretti M. 2014a. Fibrin in intervertebral disc tissue engineering. Tissue Eng Part B Rev 20(6):713721.

Colombini A, Lopa S, Ceriani C, Lovati A, Croiset S, Di Giancamillo A, Lombardi G, Banfi G, Moretti M. 2014b. In vitro characterization and in vivo behavior of human nucleus pulposus and annulus fibrosus cells in clinical grade fibrin and collagen-enriched fibrin gels. Tissue Eng Part A. DOI: 10.1089/ten. TEA.2014.0279

Cox S, Cole M, Tawil B. 2004. Behavior of human dermal fibroblasts in threedimensional fibrin clots: Dependence on fibrinogen and thrombin concentration. Tissue Eng 10(5-6):942-954.

Cui X, Boland T. 2009. Human microvasculature fabrication using thermal inkjet printing technology. Biomaterials 30((31):6221-6227. 
de Ridder L, Cornelissen M, de Ridder D. 2000. Autologous spheroid culture: A screening tool for human brain tumour invasion. Crit Rev Oncol Hematol 36(2-3): 107-122.

Dehne T, Schenk R, Perka C, Morawietz L, Pruss A, Sittinger M, Kaps C, Ringe J. 2010. Gene expression profiling of primary human articular chondrocytes in highdensity micromasses reveals patterns of recovery, maintenance, re- and dedifferentiation. Gene 462(1-2):8-17.

Fennema E, Rivron N, Rouwkema J, van Blitterswijk C, de Boer J. 2013. Spheroid culture as a tool for creating 3D complex tissues. Trends Biotechnol 31(2): 108-115.

Fu CY, Tseng SY, Yang SM, Hsu L, Liu CH, Chang HY. 2014. A microfluidic chip with a U-shaped microstructure array for multicellular spheroid formation, culturing and analysis. Biofabrication 6(1):015009.

Gerberich BG, Bhatia SK. 2013. Tissue scaffold surface patterning for clinical applications. Biotechnol J 8(1):73-84.

Ghajar CM, Chen X, Harris JW, Suresh V, Hughes CC, Jeon NL, Putnam AJ, George SC. 2008. The effect of matrix density on the regulation of 3-D capillary morphogenesis. Biophys J 94(5):1930-1941.

Giannoni P, Cancedda R. 2006. Articular chondrocyte culturing for cell-based cartilage repair: Needs and perspectives. Cells Tissues Organs 184(1):1-15.

Giannoni P, Pagano A, Maggi E, Arbico R, Randazzo N, Grandizio M, Cancedda R, Dozin B. 2005. Autologous chondrocyte implantation (ACI) for aged patients: development of the proper cell expansion conditions for possible therapeutic applications. Osteoarthritis Cartilage 13(7):589-600.

Giovannini S, Diaz-Romero J, Aigner T, Heini P, Mainil-Varlet P, Nesic D. 2010. Micromass co-culture of human articular chondrocytes and human bone marrow mesenchymal stem cells to investigate stable neocartilage tissue formation in vitro. Eur Cell Mater 20:245-259.

Gomez-Sjoberg R, Leyrat AA, Houseman BT, Shokat K, Quake SR. 2010. Biocompatibility and reduced drug absorption of sol-gel-treated poly(dimethyl siloxane) for microfluidic cell culture applications. Anal Chem 82(21):8954-8960.

Harris CA, Resau JH, Hudson EA, West RA, Moon C, Black AD, McAllister JP. 2nd. 2011. Reduction of protein adsorption and macrophage and astrocyte adhesion on ventricular catheters by polyethylene glycol and N-acetyl-L-cysteine. J Biomed Mater Res A. 98(3):425-433.

Higuera GA, Hendriks JA, van Dalum J, Wu L, Schotel R, Moreira-Teixeira L, van den Doel M, Leijten JC, Riesle J, Karperien M, van Blitterswijk CA, Moroni L. 2013. In vivo screening of extracellular matrix components produced under multiple experimental conditions implanted in one animal. Integr Biol (Camb). 5(6):889-898.

Hildner F, Concaro S, Peterbauer A, Wolbank S, Danzer M, Lindahl A, Gatenholm P, Redl H, van Griensven M. 2009. Human adipose-derived stem cells contribute to chondrogenesis in coculture with human articular chondrocytes. Tissue Eng Part A 15(12):3961-3969.

Hsu SM, Raine L, Fanger H. 1981. Use of avidin-biotin-peroxidase complex (ABC) in immunoperoxidase techniques: A comparison between $\mathrm{ABC}$ and unlabeled antibody (PAP) procedures. J Histochem Cytochem 29(4):577-580.

Huang B, Wu H, Kim S, Zare RN. 2005. Coating of poly(dimethylsiloxane) with ndodecyl-beta-D-maltoside to minimize nonspecific protein adsorption. Lab Chip 5(10):1005-1007.

Hwang CM, Ay B, Kaplan DL, Rubin JP, Marra KG, Atala A, Yoo JJ, Lee SJ. 2013. Assessments of injectable alginate particle-embedded fibrin hydrogels for soft tissue reconstruction. Biomed Mater 8(1):014105.

Jakab K, Neagu A, Mironov V, Forgacs G. 2004. Organ printing: Fiction or science. Biorheology 41(3-4):371-375.

Jakob M, Demarteau O, Schafer D, Hintermann B, Dick W, Heberer M, Martin I. 2001. Specific growth factors during the expansion and redifferentiation of adult human articular chondrocytes enhance chondrogenesis and cartilaginous tissue formation in vitro. J Cell Biochem 81(2):368-377.

Kim YJ, Sah RL, Doong JY, Grodzinsky AJ. 1988. Fluorometric assay of DNA in cartilage explants using Hoechst 33258. Anal Biochem 174(1):168-176.

Kniazeva E, Kachgal S, Putnam AJ. 2011. Effects of extracellular matrix density and mesenchymal stem cells on neovascularization in vivo. Tissue Eng Part A 17(78):905-914.

Kolesky DB, Truby RL, Gladman AS, Busbee TA, Homan KA, Lewis JA. 2014. 3D bioprinting of vascularized, heterogeneous cell-laden tissue constructs. Adv Mater 26(19):3124-3130.
Koroleva A, Gittard S, Schlie S, Deiwick A, Jockenhoevel S, Chichkov B. 2012 Fabrication of fibrin scaffolds with controlled microscale architecture by a two-photon polymerization-micromolding technique. Biofabrication 4(1): 015001.

Lagana M, Arrigoni C, Lopa S, Sansone V, Zagra L, Moretti M, Raimondi MT. 2014. Characterization of articular chondrocytes isolated from 211 osteoarthritic patients. Cell Tissue Bank 15(1):59-66.

Lopa S, Colombini A, Sansone V, Preis FW, Moretti M. 2013. Influence on chondrogenesis of human osteoarthritic chondrocytes in co-culture with donormatched mesenchymal stem cells from infrapatellar fat pad and subcutaneous adipose tissue. Int J Immunopathol Pharmacol 26(1 Suppl):23-31.

Lopa S, Colombini A, Stanco D, de Girolamo L, Sansone V, Moretti M. 2014. Donormatched mesenchymal stem cells from knee infrapatellar and subcutaneous adipose tissue of osteoarthritic donors display differential chondrogenic and osteogenic commitment. Eur Cell Mater 27:298-311.

Mauck RL, Wang CC, Oswald ES, Ateshian GA, Hung CT. 2003. The role of cell seeding density and nutrient supply for articular cartilage tissue engineering with deformational loading. Osteoarthritis Cartilage 11(12):879-890.

Meinhart J, Fussenegger M, Hobling W. 1999. Stabilization of fibrin-chondrocyte constructs for cartilage reconstruction. Ann Plast Surg 42(6):673-678.

Mironov V, Visconti RP, Kasyanov V, Forgacs G, Drake CJ, Markwald RR. 2009. Organ printing: Tissue spheroids as building blocks. Biomaterials 30(12):2164-2174.

Mooney R, Tawil B, Mahoney M. 2010. Specific fibrinogen and thrombin concentrations promote neuronal rather than glial growth when primary neural cells are seeded within plasma-derived fibrin gels. Tissue Eng Part A 16(5):1607-1619.

Moreira Teixeira LS, Sobral JC, Jin J, van Apeldoorn R, Feijen AA, van Blitterswijk J, Dijkstra C, Karperien PJ. 2012. High throughput generated micro-aggregates of chondrocytes stimulate cartilage formation in vitro and in vivo. Eur Cell Mater 23:387-399.

Murphy SV, Atala A. 2014. 3D bioprinting of tissues and organs. Nat Biotechnol 32(8):773-785.

Napolitano AP, Chai P, Dean DM, Morgan JR. 2007. Dynamics of the self-assembly of complex cellular aggregates on micromolded nonadhesive hydrogels. Tissue Eng 13(8):2087-2094.

Patra B, Chen YH, Peng CC, Lin SC, Lee CH, Tung YC. 2013. A microfluidic device for uniform-sized cell spheroids formation, culture, harvesting and flow cytometry analysis. Biomicrofluidics 7(5):54114.

Peretti GM, Randolph MA, Villa MT, Buragas MS, Yaremchuk MJ. 2000. Cell-based tissue-engineered allogeneic implant for cartilage repair. Tissue Eng 6(5): 567-576.

Piraino F, Bersini S, Pierro M, Laganà M, Redaelli A, Rasponi M, Moretti M. 2012a. Microfluidic device for cell micromass generation: Computational and experimental study. J Biomech 45:S657.

Piraino F, Selimovic S, Adamo M, Pero A, Manoucheri S, Bok Kim, Khademhosseini D. 2012b. Polyester-assay chip for stem cell studies. Biomicrofluidics 6(4):44109.

Ratnayaka SH, Hillburn TE, Forouzan O, Shevkoplyas SS, Khismatullin DB. 2013. PDMS well platform for culturing millimeter-size tumor spheroids. Biotechnol Prog 29((5):1265-1269.

Roberts WW, Kramer O, Rosser RW, Nestler FH, Ferry JD. 1974. Rheology of fibrin clots. I. Dynamic viscoelastic properties and fluid permeation. Biophys Chem $1(3): 152-160$

Sabatino MA, Santoro R, Gueven S, Jaquiery C, Wendt DJ, Martin I, Moretti M, Barbero A. 2012. Cartilage graft engineering by co-culturing primary human articular chondrocytes with human bone marrow stromal cells. J Tissue Eng Regen Med. Doi: 10.1002/term.1661

Schulze-Tanzil G. 2009. Activation and dedifferentiation of chondrocytes: Implications in cartilage injury and repair. Ann Anat 191(4):325-338.

Schuurman W, Khristov V, Pot MW, van Weeren PR, Dhert WJ, Malda J. 2011. Bioprinting of hybrid tissue constructs with tailorable mechanical properties. Biofabrication 3(2):021001.

Scotti C, Mangiavini L, Boschetti F, Vitari F, Domeneghini C, Fraschini G, Peretti GM. 2010. Effect of in vitro culture on a chondrocyte-fibrin glue hydrogel for cartilage repair. Knee Surg Sports Traumatol Arthrosc 18(10):1400-1406.

Selimovic S, Piraino F, Bae H, Rasponi M, Redaelli A, Khademhosseini A. 2011. Microfabricated polyester conical microwells for cell culture applications. Lab Chip 11(14):2325-2332. 
Steinert AF, Ghivizzani SC, Rethwilm A, Tuan RS, Evans CH, Noth U. 2007. Major biological obstacles for persistent cell-based regeneration of articular cartilage. Arthritis Res Ther 9(3):213.

Talukdar S, Nguyen QT, Chen AC, Sah RL, Kundu SC. 2011. Effect of initial cell seeding density on 3D-engineered silk fibroin scaffolds for articular cartilage tissue engineering. Biomaterials 32(34):8927-8937.

Toepke MW, Beebe DJ. 2006. PDMS absorption of small molecules and consequences in microfluidic applications. Lab Chip 6(12):1484-1486.

Tung YC, Hsiao AY, Allen SG, Torisawa YS, Ho M, Takayama S. 2011. High-throughput 3D spheroid culture and drug testing using a 384 hanging drop array. Analyst 136(3):473-478.

Whitesides GM, Ostuni E, Takayama S, Jiang X, Ingber DE. 2001. Soft lithography in biology and biochemistry. Annu Rev Biomed Eng 3:335-373.

Wolbank S, Pichler V, Ferguson JC, Meinl A, van Griensven M, Goppelt A, Redl H. 2014. Non-invasive in vivo tracking of fibrin degradation by fluorescence imaging. J Tissue Eng Regen Med.

Wolf F, Candrian C, Wendt D, Farhadi J, Heberer M, Martin I, Barbero A. 2008. Cartilage tissue engineering using pre-aggregated human articular chondrocytes. Eur Cell Mater 16:92-99.
Wu L, Prins HJ, Helder MN, van Blitterswijk CA, Karperien M. 2012. Trophic effects of mesenchymal stem cells in chondrocyte co-cultures are independent of culture conditions and cell sources. Tissue Eng Part A 18(15-16):1542-1551.

Xu F, Sridharan B, Wang S, Gurkan UA, Syverud B, Demirci U. 2011. Embryonic stem cell bioprinting for uniform and controlled size embryoid body formation. Biomicrofluidics 5(2):22207.

Zhang Z, McCaffery JM, Spencer RG, Francomano CA. 2004. Hyaline cartilage engineered by chondrocytes in pellet culture: histological, immunohistochemical and ultrastructural analysis in comparison with cartilage explants. J Anat 205(3):229-237.

Zinchenko YS, Coger RN. 2005. Engineering micropatterned surfaces for the coculture of hepatocytes and Kupffer cells. J Biomed Mater Res A 75(1):242-248.

\section{Supporting Information}

Additional supporting information may be found in the online version of this article at the publisher's web-site. 